Annuaire suisse de politique de développement

3 | 1983

Annuaire Suisse - Tiers Monde 1983

\title{
I. Négociations internationales
}

Hilar Stetter, Jacques Martin et Philippe Besson

\section{OpenEdition}

\section{Journals}

Édition électronique

URL : http://journals.openedition.org/aspd/1033

DOI : $10.4000 /$ aspd. 1033

ISSN : 1663-9669

\section{Éditeur}

Institut de hautes études internationales et du développement

\section{Édition imprimée}

Date de publication : 1 janvier 1983

Pagination : $9-86$

ISSN : 1660-5934

\section{Référence électronique}

Hilar Stetter, Jacques Martin et Philippe Besson, «I. Négociations internationales », Annuaire suisse de politique de développement [En ligne], 3 | 1983, mis en ligne le 06 décembre 2012, consulté le 08 septembre 2020. URL : http://journals.openedition.org/aspd/1033 ; DOI : https://doi.org/10.4000/ aspd. 1033 


\section{NEGOCIATIONS INTERNATIONALES}

\section{CNUCED}

\subsection{Conseil de la CNUCED: 25ème et 26ème sessions}

La 25ème session du Conseil de la CNUCED a eu lieu à Genève du 6 au 17 septembre pour la première partie et du 19 au 28 octobre pour la seconde. Les négociations ont porté principalement sur le rapport de la CNUCED sur «Commerce et développement en 1982", les préparatifs de la CNUCED VI et la coopération entre pays du Sud.

\section{Le rapport sur "Commerce et développement en 1982"}

C'est le deuxième du genre. Cette parution est maintenant annuelle. Elle présente le développement de l'économie mondiale et ses répercussions sur le commerce et l'essor des pays en développement. Le rapport analyse les difficultés majeures du développement, la détérioration accusée du climat international et les perturbations qui en résultent.

Tout part de la constatation que les pays en développement traversent actuellement la crise la plus grave depuis les années 30 et que leur taux de croissance est insuffisant.

Selon le rapport, la crise économique des pays en développement vient des fluctuations de prix dans les échanges internationaux. Les prix des matières premières sont à la baisse, le loyer de l'argent est à la hausse. Les emprunts faits à l'étranger aggravent le service de la dette et, avec les transferts de bénéfices en hausse, font pression sur les balances des paiements. La bonne marche des exportations et des récoltes audessus de la moyenne n'empêchent pas la stagnation de la croissance économique. Les succès remportés par les pays en développement dans la modernisation de leurs structures depuis le milieu des années 70 en sont réduits à néant. L'évolution internationale fait opposition aux efforts entrepris par les pays en développement.

Le climat économique est caractérisé par la lenteur de la croissance dans les pays industriels et par une inflation universelle. Avec des prix qui montent et une demande qui faiblit, le chômage s'installe dans les pays industriels et freine la croissance des pays en développement. Le ralentissement de la croissance dans les pays industriels s'est étendu aux pays en développement du fait de la baisse des importations, de la détérioration des termes de l'échange, d'un protectionnisme croissant, de l'explosion des taux d'intérêt sur les marchés internationaux des capitaux et aussi à cause de la stagnation de l'aide au développement . 
Du fait de la crise économique internationale, les institutions financières ont perdu une grande partie de leur souplesse. Ces institutions internationales de financement exigent des pays en développement qu'ils s'adaptent rapidement à un climat économique mondial devenu fort maussade. Par ailleurs, le système commercial international freine ou étouffe cet effort d'adaptation structurelle des pays en développement. Ces contradictions sont au cœur des difficultés que rencontrent beaucoup de pays en développement dans leurs relations économiques avec l'étranger; elles expliquent aussi la faible croissance de leur économie. Le système économique international manque de mécanismes de soutien aux pays en développement dans les domaines des matières premières, du commerce et des finances. Ce qui manque aussi, c'est une coopération adéquate entre les pays du Sud euxmêmes.

Le rapport aborde enfin divers thèmes économiques tels que les prestations de services dans l'économie mondiale, les pays en développement ayant une balance des paiements excédentaire, les répercussions des dépenses d'armement et de la démobilisation de l'effort de développement.

\section{La 25ème session}

Lors de la discussion du rapport, le porte-parole du "Groupe B" fit remarquer que la détérioration du climat économique avait des répercussions négatives sur les pays en développement, surtout les plus pauvres. Le rapport ne semble cependant pas accorder la même importance aux facteurs externes et au sérieux des efforts entrepris par les Etats. Le "Groupe B» aurait souhaité que le rapport fît une plus large place aux efforts nationaux qui sont finalement la clé de tout développement.

Le représentant du "Groupe des 77" qualifie le rapport d'élément important dans l'analyse de la crise actuelle. La détérioration du climat économique mondial est alarmante pour l'économie des pays en développement. Le problème crucial est maintenant le service de la dette. Les institutions internationales de financement ne peuvent jouer qu'un rôle mineur pour venir à bout de la crise. Les pays en développement sont les perdants du jeu économique mené par les pays industriels qui donnent la priorité à la lutte contre l'inflation. La baisse des exportations et la chute du prix des matières premières ont amenuisé les rentrées des pays en développement. S'il avait déjà été susceptible de fonctionner, un programme intégré des matières premières aurait empêché cette aggravation de la situation.

Le "Groupe des 77" sait fort bien qu'il appartient aux pays en développement d'améliorer eux-mêmes leurs structures économiques. II n'en est pas moins urgent de repenser l'ordre économique mondial et de grossir les apports financiers destinés aux pays en développement, d'ouvrir les marchés des pays industriels et de mettre en vigueur le pro- 
gramme intégré des matières premières, sans préjudice des autres mesures à prendre.

La deuxième partie de la 25ème session a été placée sous le signe des préparatifs de la négociation sur la coopération économique entre les pays en développement. C'est en 1976 déjà que le Conseil avait décidé de former un comité de la CNUCED pour l'étude de la coopération économique entre les pays en développement. Les tâches de ce comité furent précisées lors de la CNUCED $\vee$ en 1979. A ce jour, des difficultés de procédure ont empêché le comité de commencer ses travaux. On ne sait toujours pas qui aura le droit d'en faire partie. Les négociations du système s'inspirent normalement du principe d'universalité, de l'égalité souveraine et de la transparence. Si l'on applique ces principes au comité, cela revient à dire que tous les membres de la CNUCED ont un droit égal de s'y faire entendre.

Le "Groupe des 77» défend cependant le point de vue qu'il peut luimême désigner les participants aux conversations sur la coopération économique entre pays en développement dans le cadre de la $\mathrm{CNU}$ CED. Les pays industriels se sont jusqu'à maintenant opposés à cette exigence pour ne pas consentir au "Groupe des 77" le droit d'exclure des entretiens des pays en développement $n^{\prime}$ appartenant pas à ce groupe, par exemple Israël ou la Turqiue.

Le comité aurait comme tâche principale la mise au point entre les pays en développement d'un système universel de préférences commerciales; il devrait aussi développer la coopération entre les organismes commerciaux officiels des pays en développement et contribuer à la création d'entreprises commerciales multilatérales, toujours dans les pays en développement.

Au cours de la deuxième partie de la 25ème session, un vote sur des questions de procédure permit au "Groupe des 77 " d'imposer son point de vue. On décida par ailleurs que seuls les participants auraient accès aux documents de la CNUCED contenant des informations confidentielles sur les travaux de ce comité. Tous les membres de la CNUCED ont cependant droit aux documents fondamentaux sur la coopération économique entre pays en développement et aux rapports sur l'état des négociations. Le secrétariat de la CNUCED est prié de fournir une aide technique et administrative; il convoquera les pays en développement à une négociation sur le système des préférences commerciales.

Le représentant de la Suisse au Conseil regretta qu'on eût procédé à un vote en conseil au lieu de continuer à négocier et se montra inquiet des répercussions négatives de ce vote sur la coopération entre Etats du Sud, coopération que la Suisse continue d'encourager. L'opposition manifestée contre la résolution avait pour cause le respect du principe d'universalité. 


\section{La 26ème session}

La 26ème session du Conseil de la CNUCED, qui s'est tenue à Genève du 18 au 22 avril 1983, a surtout traité des questions commerciales et de l'endettement des pays en développement. Le secrétariat de la CNUCED fit remarquer qu'il devenait nécessaire de créer un comité spécial à l'intérieur du Conseil, afin de procéder à un examen annuel du protectionnisme et de la modification des structures et de rédiger des recommandations. A la veille de la CNUCED VI, cette session n'a pris aucune résolution. Elle a été suivie de la 12 ème réunion extraordinaire du Conseil qui a procédé aux préparatifs de la CNUCED VI.

\section{Sources}

Chronique des NU, décembre 1982.

CNUCED, Communiqué de presse TAD/INF/B63, 1373-1379, 1389.

CNUCED, TD/B/930; TD/B/934; TD/B/957.

\subsection{Produits de base}

La constitution d'un Fonds commun des matières premières progresse lentement. Les $\mathrm{EU}$ et les pays à commerce étatisé continuent de se montrer réservés. L'accord sur le jute a abouti. Un accord sur le sucre et un autre sur les bois tropicaux sont en cours de négociation. Les pays producteurs d'étain et de coton ont fondé leur propre organisation.

\subsubsection{Fonds commun pour les produits de base}

En juin 1982, les 21 Etats qui avaient ratifié dans les délais I'accord sur le Fonds commun pour les produits de base décidèrent de repousser au 30 septembre le date limite de ratification. Le Fonds pourra fonctionner au moment où 90 Etats au moins auront ratifié l'accord et où deux tiers au moins des contributions ordinaires et la moitié des prestations volontaires au deuxième compte seront assurées. Lors de la CNUCED $\mathrm{VI}$, qui fut I'une des étapes vers la création du fonds, quatre nouveaux Etats ratifièrent l'accord et seize y apposèrent leur signature. Ce qui revient à dire qu'à fin juin 1983 I'accord sur la création d'un Fonds commun des matières premières avait été signé par 108 Etats et ratifié par 53 pays. Par la suite, 12 pays du "Groupe B" l'ont signé et ratifié, cependant que 11 pays se contentaient de le signer. L'Islande n'a pas encore pris position. Les EU ne donnent aucune assurance quant à leur volonté de ratifier le texte dont ils critiquent l'effort de stabilisation des prix par le recours à des accords distincts sur les matières premières.

Quarante pays du "Groupe des 77" ont ratifié l'accord sur le fonds, 44 I'ont signé et 38 sont encore dans l'expectative. Maintenant que la 
Malaysia, grand producteur de matières premières, a annoncé qu'elle ratifierait I'accord, $d^{\prime}$ autres pays en développement vont sans doute suivre. Aucun pays du "Groupe $D$ " n'a pour le moment signé ou ratifié l'accord sur le Fonds commun pour les produits de base.

Pour sa part, la Chine a souscrit à l'accord sans attendre la prolongation des délais de ratification. A la fin de la CNUCED VI, les Etats qui avaient ratifié l'accord avaient fourni $36 \%$ des contributions directes exigées. Les conditions prévues pour l'entrée en vigueur de l'accord ne seront cependant pas réunies si les EU et les pays du "Groupe D" n'entrent pas dans la danse. Dès avant la CNUCED VI, le fonds de développement des pays de l'OPEP avait offert de prendre en charge les contributions des pays les moins avancés; lors de la conférence, la Norvège fit savoir qu'elle verserait la contribution pour cinq pays parmi les plus pauvres. Les Etats de l'OCDE prirent ies mêmes dispositions en faveur des trois Etats qui ont été classés récemment dans le groupe des pays les moins avancés.

\subsubsection{Les accords spécifiques sur les produits de base}

\section{Accord international sur le café}

Dans sa réunion du 6 au 25 septembre 1982, le Conseil international du café a décidé de prolonger jusqu'en septembre 1983 l'accord actuel sur le café et d'appuyer le texte du nouvel accord qui avait été élaboré après de longs préparatifs. S'il est ratifié par un nombre d'Etats suffisant, ce qui paraît vraisemblable, ce nouveau document entrera en vigueur au 1 er octobre 1983 et pour une durée de six ans. En 1982 1983, les prix du café ont pu être maintenus dans les limites de prix prévues. Des diminutions de quotas ont permis de s'opposer à l'offre excédentaire.

Plus de $99 \%$ des exportations mondiales viennent des pays producteurs membres de l'accord international. Certaines quantités sont vendues à des pays consommateurs qui n'adhèrent pas à l'accord. Ces exportations-là ne sont pas soumises au calcul des quotas prévu. Le marché international du café est couvert à $80 \%$ par les dispositions de I'accord. Le nouvel accord qui n'est pas encore en vigueur ressemble beaucoup au précédent. Son principal instrument de soutien des prix est l'attribution de quotas d'exportation aux divers pays producteurs. Les petits exportateurs de café ont reçu un contingent global. II n'y a pas de limitation des exportations vers les pays qui ne sont pas membres de l'accord.

Le quota global des exportations pour 1982-1983 a été fixé à 52,8 millions de sacs. La part du Brésil s'est élevée à $30,8 \%$ et celle de la Colombie à $16,3 \%$. Les exportateurs asiatiques, notamment I'Indonésie, se sentent défavorisés par rapport aux pays latino-américains. Ces quotas de base sont également valables durant la première année du 
nouvel accord. Lors des négociations, la discussion a, une fois de plus, porté sur d'éventuels quotas différenciés en fonction des diverses sortes de café. L'efficacité du nouvel accord dépendra beaucoup de la manière dont on parviendra à faire baisser quelque peu une offre fortement excédentaire ces dernières années, alors que la demande est stagnante; elle avait beaucoup progressé précédemment. Pour I'heure, les ventes à des prix fortement réduits à des pays qui ne font pas partie de I'accord sont préjudiciables à un bon fonctionnement de l'accord international.

Le nouvel accord pourra entrer en vigueur au 1 er octobre 1983 à condition qu'au moins 20 pays exportateurs réunissant au minimum $80 \%$ de l'offre mondiale et 10 pays consommateurs représentant le $80 \%$ de la demande globale le ratifient ou s'engagent à en respecter les clauses. A fin juin, 62 pays avaient signé I'accord, de sorte que le texte pourra entrer en vigueur, semble-t-il, sans difficultés.

En septembre 1982, le Conseil fédéral a souscrit à la prolongation de la validité de l'accord international sur le café pour un an. En juin 1983, il a décidé de signer le nouvel accord international sous réserve de ratification et d'en respecter les dispositions à titre provisoire. Cet accord sera présenté à l'approbation du parlement au cours de la session d'automne.

\section{Autres accords sur les produits de base}

$\mathrm{Vu}$ l'offre de cacao fortement excédentaire et les faibles possibilités d'intervention de l'Organisation internationale du cacao, l'accord international sur le cacao existant $n$ 'a pu empêcher les prix de stagner audessous de la limite qu' on cherchait à maintenir par des achats de soutien. Les perspectives d'une mauvaise cueillette déterminèrent pour finir une forte hausse des prix, le prix mondial dépassant parfois la limite inférieure des prix de soutien, cela sans intervention du stock compensatoire de I'OICC. Le fonctionnement de l'accord continue d'être entravé par le fait que le premier pays producteur (Côte-d'Ivoire) et le premier pays consommateur (EU) n'en font pas partie. C'est pourquoi le Conseil du cacao a décidé en juillet d'accélérer les négociations sur un nouvel accord amélioré. Les Etats non membres sont invités aux travaux préparatoires au sein de l'Organisation du cacao; si tout va bien, une nouvelle conférence de I'ONU sur le cacao sera convoquée en mai 1984.

Au cours du deuxième semestre 1982, l'Accord international sur le caoutchouc naturel a procédé à des achats par son stock de compensation afin de maintenir les prix dans les limites prévues. A la fin du premier semestre 1983, les stocks s'élevaient à $270.000 \mathrm{t}$, alors qu'on avait arrêté à 400.000 t la capacité du stock normal de compensation. Au cours de ce premier semestre 1983, les prix ont de nouveau été à la hausse, du fait d'une demande plus élevée de l'industrie auto- 
mobile. La Malaysia, premier producteur de caoutchouc naturel, tente toujours de ranimer l'association des pays producteurs de caoutchouc, une organisation parallèle à I'OICN. La Thaïlande et I'Indonésie sont deux autres grands producteurs.

L'accord international sur l'étain est provisoirement en vigueur. Pour qu'il le soit définitivement, il ne lui manque que le quota indispensable de $80 \%$ des pays consommateurs. Cette proportion n'est pas atteinte du fait de l'ostracisme des EU, premier pays importateur. Les prix sont bas, la demande est faible, on ne cesse de produire au-delà des besoins; en juillet 1982, le Conseil international de l'étain décida pour la première fois d'introduire des contrôles à l'exportation en vertu du sixième accord sur l'étain. Ces contrôles ont été maintenus. Des achats de soutien pour les stocks de compensation ont été effectués à plusieurs reprises.

Le Conseil fédéral a ratifié en avril 1983 I'accord sur l'étain, après que le Parlement lui en eut donné I'autorisation en octobre 1982.

Diverses réunions de pays producteurs d'étain ont eu lieu I'an passé dans le but de fonder une Organisation des pays producteurs d'étain (Association of Tin Producing Countries - ATPC). C'est la Malaysia qui a pris l'initiative de cette entreprise. En juin 1982 déjà, la Malaysia, I'Indonésie et la Thaïlande étaient tombées d'accord pour fonder cette organisation. D'autres rencontres eurent lieu et c'est finalement en juin 1983 que fut ratifiée la décision de mettre sur pied ce groupement de producteurs. En font déjà partie les trois pays déjà mentionnés. Les travaux ont commencé en août. La Bolivie, le Nigeria, le Zaïre et l'Australie se sont prononcés en faveur de la création de cette association. De petits pays producteurs feront sans doute bientôt acte de candidature. Ce rassemblement devrait améliorer la situation des producteurs sur les marchés et à la table des négociations quand les prix de l'étain sont à la baisse sur le marché mondial. La nouvelle association a également pour but d'améliorer la commercialisation de l'étain et de développer les recherches en vue de nouvelles utilisations.

D'autres consultations ont eu lieu dans le cadre de la CNUCED sur toute une série de matières premières qui n'ont pas encore fait l'objet d'un accord. Une commission préparatoire a étudié pour la première fois l'éventuelle conclusion d'un accord sur la bauxite (du 8 au 12 novembre 1982, à Genève). Les pays en développement se prononcèrent en faveur d'interventions étatiques dans le cadre d'un accord et insistèrent sur une indispensable transparence des prix. Les pays industriels firent ressortir les structures verticales de la production, la forte concentration des capitaux nécessaires et les difficultés du transfert technologique. D'autres réunions suivront. Par ailleurs, des rencontres d'experts ont permis de parler du manganèse, des bananes et du thé. 
Lors de la CNUCED VI, des représentants du groupe d'Izmir qui rassemble 23 pays en développement producteurs de coton firent connaître la création d'une association des pays producteurs de coton (AIPC). En effet, l'Egypte, le Mexique, le Pakistan, la Syrie et la Turquie ont signé le texte créant cette association. Ces pays représentent $25 \%$ des exportations mondiales de coton. D'autres pays en développement s'uniront à eux.

L'AIPC améliorera la position des pays membres lors des négociations et développera la production, la transformation et le commerce du coton.

A la CNUCED, les pourparlers concernant la conclusion d'un accord sur le coton sont dans l'impasse. Le groupe d'Izmir exige la création d'un mécanisme de stabilisation des prix au moyen de stocks compensatoires. Certains pays industriels acceptent tout au plus de discuter des progrès de la commercialisation, de la recherche scientifique et du développement. Un accord pourrait intervenir sur ces points-là, les mesures à prendre étant financées par le deuxième compte du Fonds commun.

\section{Sources}

UNCTAD VI - Press Release, 20 juin 1983.

UNCTAD, TD/273.

CNUCED, Communiqué de presse, TAD/INF 1472.

NZZ, 27.9.1982; 18-19.6, 14.7.1983.

\subsubsection{Accord international sur le jute}

La conférence de l'ONU sur le jute a réalisé I'accord international sur le jute et les articles en jute. Ce texte prévoit des projets techniques, des mesures d'expansion commerciale, mais rien qui favorise la stabilisation des prix.

C'est à Genève, du 20 septembre au 1er octobre 1982, que les délégués des 53 Etats se sont retrouvés à la troisième session de la conférence internationale des Nations Unies sur le jute et les articles en jute. A l'issue de la conférence, les participants firent connaître leur projet d'entente internationale (accord international sur le jute et les articles en jute).

Les négociations avaient commencé en 1981, précédées depuis 1978 par les réunions d'un groupe préparatoire constitué selon les recommandations du programme des matières premières de la CNUCED IV de Nairobi. Après les deux premières rondes, ces négociations initiales avaient tant progressé qu'on aurait presque pu conclure l'accord sur le jute. Le Bangladesh, premier pays exportateur de jute, et I'Inde, premier producteur mondial de jute, ne parvinrent cependant pas à s'entendre sur le nombre de voix respectives. 
L'accord sur le jute poursuit cinq buts principaux:

- améliorer les structures du marché de ce produit;

- maintenir les marchés actuels et en ouvrir de nouveaux;

- améliorer la capacité concurrentielle du jute et des articles en jute;

- améliorer la qualité et augmenter la production d'un jute de meilleure qualité;

- augmenter la production, le volume des exportations et des importations du jute et des articles en jute.

Ces objectifs doivent être atteints par l'acceptation, le financement et la réalisation de projets relevant de la recherche et du développement, de l'expansion commerciale et de l'abaissement des coûts.

Une organisation internationale du jute est créée pour mettre en vigueur I'accord réalisé. Ayant son siège à Dacca, elle garantit que l'accord sera respecté et en surveille les mécanismes. L'organe directeur de l'organisation du jute est le conseil du jute qui décide de la mise en œuvre des projets. Pays producteurs et pays consommateurs disposent de 1.000 voix au conseil pour chacun des deux groupes, chaque pays ayant droit à un nombre convenu de voix pondéré par la part prise aux marchés.

Les cotisations des pays membres couvrent le financement des frais courants. Le financement des projets réalisés en vertu de l'accord sera à la charge du deuxième compte du Fonds commun des matières premières, des institutions financièrs régionales et internationales, le tout étant complété par des prestations volontaires. L'accord aurait pu entrer en vigueur au plus tôt au 1er juillet 1983, s'il avait été signé à cette date par au moins trois pays exportateurs représentant une proportion de $85 \%$ de l'ensemble des exportations de jute et par au moins vingt pays importateurs avec $65 \%$ au minimum du total des importations. Le quorum ne fut pas atteint par les pays importateurs. Le secrétaire général de l'ONU invite maintenant les Etats signataires à faire entrer I'accord en vigueur entre eux au 1er janvier 1984.

L'accord est entièrement axé sur le financement de projets; il ne prévoit aucune des mesures de stabilisation des prix, telles qu'elles figurent au premier guichet du Fonds commun pour les produits de base. Au cours des négociations, les pays en développement ont réclamé de telles mesures et, auprès de l'Organisation du jute, la possibilité de contracter des emprunts. Les pays industriels pensent que cet accord pourrait ouvrir la voie à d'autres conventions du même genre.

La Suisse était représentée à la table des négociations. Elle fit remarquer que cet accord serait peut-être à même d'accélérer la conclusion d'autres accords sur les matières premières conformes aux dispositions du deuxième guichet du Fonds commun. La Suisse n'est pas parvenue à signer l'accord dans les délais prévus. Un message devra d'abord être publié à ce sujet. 
Côté exportations, c'est le Bangladesh qui domine le marché avec $56,7 \%$ des exportations mondiales de 1979 à 1981. Vient ensuite I'Inde, premier pays producteur, avec $31,4 \%$ des exportations, précédant la Thaïlande $(7,4 \%)$ et le Népal $(3,5 \%)$. Les ventes de jute font $65 \%$ des recettes du Bangladesh aux exportations et celles du Népal $30 \%$. Côté importations, les EU (17\%), la CEE (16\%), I'URSS (12\%) et le Pakistan $(8 \%)$ sont les pays les plus importants.

Au cours des années 70 , les prix du jute n'ont cessé de baisser, même si le volume des ventes était d'abord constant, les exportations vers les EU s'inscrivaient en forte baisse. A la longue, la diminution des exportations engendra une diminution de la production. De 1972 à 1974, les exportations furent encore de $785.000 \mathrm{t}$, mais plus que de 534.700 t en 1981-1982. Compte tenu de l'inflation, les prix du jute sont tombés en 1981-1982 à $75 \%$ de ce qu'ils étaient en 1970-1971 et même à $65 \%$ au Bangladesh et à $25 \%$ au Népal.

Si le jute se vend beaucoup moins dans les pays industriels, c'est à cause de la concurrence des fibres synthétiques, de la mutation technique des transports (containers) et d'un marketing déficient. Le recul des ventes dans les pays industriels a été en partie compensé par l'augmentation du volume des échanges entre pays du Sud.

Avec sa quote-part de $0,267 \%$ aux importations mondiales, la Suisse joue un rôle marginal sur le marché du jute, mais elle est une des plaques tournantes du commerce international du jute à cause des grandes firmes commerciales domiciliées chez elle. Le Bangladesh et le Népal sont deux pays où la coopération suisse au développement s'engage beaucoup; le programme de développement des importations donne une place de choix au jute en tant que matière première.

\section{Sources}

CNUCED, Accord international de 1982 sur le jute et les articles en jute, TD/Jute/11.

CNUCED, Communiqué de presse TAD/INF/1381, 1384.

ONU-Chronique, novembre 1982.

$E+D, 13 / 1982$.

NZZ, 2-3.10.1982.

\subsubsection{Conférence de l'ONU sur le sucre}

Les pays producteurs et les pays consommateurs s'acheminent vers un nouvel et efficace accord sur le sucre dont les mécanismes suscitent encore de fortes divergences d'opinions. La CEE est au premier plan des négociations. La Suisse se montre intéressée à ce nouvel accord. 
La première session de la conférence de I'ONU réunie pour mettre au point un nouvel accord international sur le sucre a eu lieu à Genève du 2 au 20 mai 1983. 79 Etats et la CEE y étaient représentés par des délégations parlant au nom de 57 pays exportateurs et de 22 pays importateurs de sucre. Des divergences d'opinions, insurmontables pour le moment, ont rendu nécessaire la convocation d'une deuxième session en octobre 1983. Dans l'intervalle, d'autres consultations ont eu lieu en juillet au siège de l'Organisation internationale du sucre à Londres.

Entre les Etats européens et les EU, un premier accord avait été conclu en 1902. Au sein de la CNUCED, les premières discussions concernant un accord international sur le sucre eurent lieu en 1965 déjà. Elles débouchèrent sur la conclusion d'un accord international sur le sucre, mais sans la participation des Etats de la CEE. L'accord comportait un système souple de quotas d'exportation. Les mécanismes de régularisation des prix prévus étaient cependant inadaptés aux forces en présence sur les marchés. En 1977, un nouvel accord fut signé, une fois de plus sans la participation de la CEE. Comme les précédents, ce document ne put empêcher les prix de monter fortement en 1980 ni de baisser en 1982 au-dessous du niveau des coûts de production.

Le but des négociations actuelles est de remplacer par un nouvel accord le document présentement en vigueur pour une durée de cinq ans, qui se révèle inefficace. Au début des entretiens, on n'était au clair ni sur les mécanismes du nouvel accord, ni sur son financement, ni sur l'adhésion de la CEE. Le nouvel accord devrait tendre à stabiliser le commerce mondial du sucre et à éviter les fluctuations de prix.

La CEE occupe une place de choix à la table des négociations sur ce nouvel accord. Son absence dans le passé explique en grande partie l'inefficacité des accords précédents. La CEE négocie donc en position de force. Les intérêts qui se manifestent ne sont pas étroitement ceux des pays en développement et ceux des pays industriels, mais plutôt ceux des grands pays importateurs et des premiers pays exportateurs, catégorie où se trouvent de nombreux pays en développement. II y a enfin les pays exportateurs petits et moyens. On espère en arriver avec le temps à un marché bien approvisionné à des prix stables.

\section{Les points essentiels de la négociation}

La nature des mécanismes de régularisation des prix et leur financement sont les deux questions principales à discuter. La CEE propose un mécanisme basé sur la constitution de stocks où chaque pays $\mathbf{s}^{\prime}$ engagerait à entreposer ses excédents de production. Ces stocks seraient gérés selon une entente internationale. On y prélèverait de quoi faire baisser les prix en cas de hausses exagérées. Les importateurs aussi bien que les exportateurs financeraient ces stocks. Selon la part prise au marché mondial par leurs exportations ou leurs importations, les 
Etats membres assumeraient des devoirs et jouiraient de droits différenciés. Les dix premiers producteurs de sucre deviendraient ainsi le groupe le plus important au sein de l'accord.

Les pays en développement ont d'abord défendu l'idée des quotas d'exportation et d'un stock international de compensation. Les petits pays exportateurs désiraient des dérogations au système des quotas d'exportation. Les pays importateurs se prononcèrent contre leur participation financière à la gestion des stocks.

On ignore encore le coût du mécanisme de réglementation du marché et d'où viendrait son financement. On parle de la possibilité de prélever une taxe sur les échanges commerciaux et d'obtenir des facilités de financement du FMI pour financer les stocks compensatoires. Si l'entente se fait à propos de la constitution de stocks, on fera appel au Fonds commun après son entrée en vigueur, son deuxième compte pouvant même financer les programmes de diversification de la production sucrière. La discussion a encore porté sur l'établissement d'une échelle des prix et sur les niveaux d'intervention.

Reste à savoir si les mécanismes à mettre en place en vertu du nouvel accord seront assez tranchants pour assurer un contrôle efficace du marché et si leurs différents rouages (quotas d'exportation et stocks) tourneront sans grincer.

Les résultats obtenus à ce jour montrent que les Etats de la CEE s'intéressent à un nouvel accord et qu'ils ont joué un rôle actif dès le début des négociations. Ils refusent toutefois de souscrire à un accord qui stabiliserait les marchés au moyen des quotas d'exportation. La CEE voudrait que le nouvel accord institue un vigoureux mécanisme de contrôle tenant compte des possibilités réelles d'exportation des Etats en présence. C'est à cette condition que les stocks pourraient être gérés convenablement.

\section{La position de la Suisse}

La Suisse $n$ 'avait pas signé l'ancien accord, mais elle a participé à cette conférence. Dans l'optique de la Suisse, le nouvel accord ne fonctionnera bien que si la CEE en fait partie. Un système de quotas d'exportation combiné avec des stocks accrus fournirait un meilleur mécanisme régulateur que la proposition de la CEE; l'opinion de la Suisse rejoint là celle d'autres pays importateurs. En pratique, les chances de succès paraissent minces. La Suisse désire éviter qu'on accorde aux dix premiers pays exportateurs le financement collectif de stocks provenant d'excédents de production qui ont leur origine dans des mesures protectionnistes. L'accord ne fonctionnera qu'au moment où l'on parviendra tout à la fois à freiner la surproduction et à réduire les excédents structurels. 


\section{Le marché du sucre}

La production mondiale de sucre provient à $60 \%$ de la culture de la canne dans les régions tropicales et subtropicales et à $40 \%$ des cultures de betteraves sucrières. La production dans son ensemble tend à être excédentaire, les prix sont souvent subventionnés au gré de la politique agricole suivie par les différents pays; les échanges internationaux sont réglés par des accords bilatéraux et multilatéraux.

Ces accords reconnaissent aux exportateurs choisis le droit à des prix préférentiels. De cette manière, le marché libre ne reçoit plus qu'environ $20 \%$ de la production. Le sucre se traite aux bourses de New York, de Londres et de Paris. La tendance à la surproduction fait pression sur les prix. En ce qui concerne le sucre de canne, les prix ne couvrent plus les coûts de production. Côté demande, la consommation de sucre dans les pays industriels est stagnante. Dans les pays en développement, où la consommation s'établit en moyenne à des niveaux inférieurs, on ne pourrait absorber davantage de sucre que si le pouvoir d'achat s'élevait.

Si la production mondiale s'est élevée à 100 millions de t en 1982, la consommation n'a été que de 91 millions de $t$. Les premiers producteurs ont été la CEE, I'URSS, le Brésil, Cuba, l'Inde et les EU. Pour un total de 30 millions de $t$ aux exportations, les principaux fournisseurs ont été Cuba, la CEE, le Brésil, I'Australie, la Thaïlande et les Philippines. Les importateurs les plus importants ont été l'URSS, les EU, le Japon et la Chine. L'état des stocks s'établissait fin 1982 à 50 millions de $t$, ce qui équivaut à plus de la moitié de la consommation mondiale en un an.

Pays industriels et pays en développement interviennent sur le marché du sucre tant du côté de l'offre que du côté de la demande. Le taux d'autoapprovisionnement est en général élevé. $25-30 \%$ de la produc tion parviennent sur les marchés internationaux, dont le tiers environ par le fait d'accords (comme par exemple entre Cuba et le COMECON ou entre la CEE et les Etats des ACP). En 1980, les deux tiers des exportations mondiales ont été le fait de pays en développement. Les pays industriels occidentaux ont pu revendiquer à peine $50 \%$ des importations, un peu plus du quart étant absorbé par les pays en développement.

La Suisse demande au marché international environ $138.000 \mathrm{t}$ de sucre cristallisé, achats qu'elle couvre à peu près entièrement auprès des pays membres de la CEE. Ces importations représentent environ $50 \%$ de la consommation nationale.

\section{Sources}

CNUCED, TAD/INF (1449-1458).

icda-news 4/1983.

NZZ, 10.5.1983. 


\subsubsection{Conférence de I'ONU sur les bois tropicaux}

Un accord sur les matières premières concernant les bois tropicaux est en gestation. On ne prévoit pas de mesures de stabilisation des prix. Les organisations internationales et les petits pays utilisateurs, dont la Suisse, espèrent que l'accord tiendra compte de l'équilibre écologique.

Après six ans de discussions liminaires entre producteurs et consommateurs, la première conférence de l'ONU sur les bois tropicaux s'est réunie à Genève du 14 au 31 mars 1983, dans le cadre de la CNUCED. Les représentants de 64 pays y ont pris part. Ils représentaient à peu près $90 \%$ du commerce mondial des bois tropicaux.

Les bois tropicaux sont I'une des 18 matières premières qui doivent faire l'objet d'un accord international en vertu du Programme intégré des matières premières. Le marché mondial des bois tropicaux s'est fort développé au cours des cinquante dernières années. A la fin des années 70 , il portait sur des quantités 18 fois plus élevées que trente ans plus tôt. De 1978 à 1980, les transactions en bois tropicaux ont dépassé 7 milliards de dollars EU par an. Elles ont toutefois faibli ces deux dernières années.

A l'issue de la deuxième guerre mondiale, les Philippines étaient au premier rang des pays exportateurs; la Malaysia et I'Indonésie ont pris sa place au cours de la dernière décennie. Ces deux pays monopolisent les deux tiers des exportations universelles. La Côte-d'Ivoire et le Brésil sont deux autres grands pays exportateurs. Du côté des importateurs, c'est le Japon qui est le premier acheteur de bois tropicaux en s'adjugeant un tiers du marché, suivi à parts presque égales par les pays de la CEE et des EU.

\section{L'état des négociations}

A l'issue des travaux préparatoires, la conférence avait à se prononcer sur quatre projets d'accord (pays producteurs/Japon/EU/Scandinavie). La convention proposée comporte quatre éléments indispensables à la coopération internationale: recherche et développement, sylviculture et reboisement, transformation plus poussée de la matière première dans les pays en développement et amélioration de la transparence des marchés. Avec un accord ainsi orienté, on n'a pas jugé nécessaire de créer un mécanisme de stabilisation des prix.

Les projets de l'accord doivent être financés par des ressources prélevées au deuxième guichet du Fonds commun des matières premières. Les institutions financières régionales et internationales peuvent fournir d'autres apports financiers; les gouvernements peuvent aussi verser des contributions volontaires. Les frais courants sont couverts par les cotisations des Etats membres. 
Rien qu'au chapitre recherche et développement en bois tropicaux, la conférence avait déjà à se prononcer sur 42 projets, mais la discussion sur les critères du choix de ces projets n'est par terminée. Transfert de technologie, formation professionnelle, standardisation des produits et augmentation des investissements doivent faire progresser la transformation des bois dans les pays producteurs. Le reboisement et la sylviculture auront à s'opposer à la destruction progressive des forêts tropicales.

Une deuxième session de la conférence se tiendra avant la fin de 1983. On pense que l'accord pourra y être paraphé. L'organisation internationale pour les bois tropicaux serait ainsi à même de se mettre au travail dès 1985.

Les travaux ont déjà bien progressé, mais on n'a pas encore pu s'entendre concernant le but à atteindre par cette convention. Les grands pays producteurs donnent la priorité à une réglementation des prix; les principaux pays consommateurs placent au premier rang le commerce proprement dit et les autres pays consommateurs avancent I'argument écologique. Sur proposition des organisations spécialisées de I'ONU (PNUE/FAO) et avec l'appui des pays nordiques et de la Suisse, on accordera la priorité à une exploitation écologique de la forêt tropicale. On tiendra donc compte du maintien de l'équilibre écologique régional, de la protection des essences et des nécessités du reboisement.

Certaines questions techniques restent à régler, par exemple le choix du siège de cette "Organisation internationale pour les bois tropicaux" qui n'existe pas encore. Par contre, on a déjà décidé que les pays producteurs et les pays consommateurs se répartiraient les voix à raison de $50 \%-50 \%$. II faudra, certes, attribuer les voix à l'intérieur de chaque groupe. Les Etats membres ont encore à s'entendre sur le nombre des commissions appelées à étudier les dernières difficultés de I'accord prévu.

L'ambassadeur F. Blankart, délégué de la Suisse, a fait ressortir ce qu'il juge être les deux motivations essentielles de l'accord: le développement du commerce international et le maintien de l'équilibre écologique, toutes les deux étant d'égale importance. L'exploitation de la forêt tropicale ne peut être assurée que par son maintien. II y a donc lieu de collaborer avec le Programme des Nations Unies pour I'environnement.

\section{Sources}

CNUCED, Communiqué de presse TAF/INF 1433-35.

CNUCED, bulletin 185, juillet 1982; 192, avril 1983.

NZZ, 8.12.1982; 2.4.1983. 


\subsection{Nouveau programme substantiel d'action pour les pays les moins avancés}

Décidé en 1981, le "Nouveau programme substantiel d'action» ne déploie pas encore ses effets et il est trop tôt pour établir un bilan provisoire. La Suisse entend doubler sa contribution aux pays les plus pauvres. Elle a effectué en 1983 un versement de 5 millions de francs au Fonds des PMA de I'ONU.

C'est du 11 au 20 octobre 1982, à Genève, qu'a eu lieu la première des conférences multilatérales périodiques appelées à se pencher sur les difficultés des pays en développement les plus pauvres. Ces conférences avaient été décidées en 1981, lors de la conférence de Paris sur les pays les moins avancés. $Y$ avaient pris part les représentants des pays les plus pauvres, des pays donateurs, des Nations Unies et de leurs organisations spécialisées ainsi que des organisations nongouvernementales.

Lors de cette conférence de 1981 à Paris, les Etats avaient convenu d'un "nouveau programme substantiel d'action" afin d'aider les pays les moins avancés dans la voie de leur développement national. La plupart des pays industriels se dirent prêts à consacrer, au cours des années $80,0,15 \%$ de leur PSB aux prestations en faveur des pays les plus pauvres; d'autres pays doubleront à tout le moins le volume de leur aide aux PMA. L'effort ne sera pas seulement quantitatif. II portera aussi sur les formes de l'aide consentie.

L'aide internationale complète opportunément les efforts accomplis par les pays les plus pauvres dans la voie du développement. Au cours des années 70, le PSB de ces pays n'a progressé que d'une manière insuffisante en chiffres réels. Il a même baissé de 0,6\% en 1981 pour s'établir à une moyenne de 220 dollars EU par personne. On pense que le niveau des 240 dollars ne sera atteint qu'en 1990. Les éléments les plus négatifs sont l'affaissement de la production vivrière et la détérioration de la balance des paiements. Les recettes d'exportations couvrent une marge toujours plus faible des dépenses d'importations.

La CNUCED a constaté que l'aide aux pays les plus pauvres avait baissé avant le début de la conférence de Paris. Au cours de 1981 également, I'aide accordée aux PMA atteint des niveaux encore plus bas en chiffres nominaux et réels. Même si les promesses de secours financier données à Paris par les pays donateurs devaient être tenues, les PMA n'en connaîtraient pas moins une pénurie de liquidités pour financer leurs plans de développement.

Cette deuxième réunion des institutions d'entraide et des pays en développement les plus pauvres $\mathrm{s}^{\prime}$ attache maintenant à simplifier les mécanismes administratifs de l'aide, à les rationaliser et à mieux les adapter aux besoins des pays bénéficiaires. L'aide pourrait être amélio- 
rée à condition:

- d'être accordée sous forme de don ou à tout le moins de crédit à des conditions de faveur;

- de n'être pas liée, car l'aide liée est néfaste pour le pays qui la reçoit. L'assemblée générale de I'ONU demande que I'aide ne soit pas liée; quand ce n'est pas possible, il faudrait en atténuer les servitudes et les inconvénients;

- que les crédits prélevés sur des fonds publics par la coopération au développement soient transformés en dons, cela afin de réduire l'endettement;

- de raccourcir les délais entre préparation et réalisation des projets, tenir compte de l'inflation durant la période de financement du projet.

Si I'on veut adapter l'aide aux réalités du pays bénéficiaire, il faut veiller à :

- stabiliser la balance des paiements et agir au niveau économique et politique sur les prix des matières premières plutôt que de financer des projets, là où les pays bénéficiaires manquent de devises et où les facteurs de production sont déficients;

- amener les pays donateurs à financer les frais de gestion et les dépenses locales pour les projets;

- améliorer dans les pays bénéficiares la possibilité de préparer et de réaliser les projets;

- améliorer entre les pays donateurs la synchronisation des prestations.

\section{L'aide de la Suisse aux pays les plus pauvres}

En Suisse, on a pensé que cette deuxième session venait trop tôt pour qu'on puisse déjà dresser un bilan provisoire. Les retombées du programme adopté ne sont pas encore connues. Les discussions qui ont eu lieu à la CNUCED VI concernant ce programme ont buté sur le même écueil. La Suisse pense cependant que les tables rondes réunissant les institutions d'entraide et les pays bénéficiaires jouent un rôle important dans le bon déroulement du programme.

Notre pays a l'intention de doubler au cours des années 1981-1985 ses prestations d'entraide aux pays les plus pauvres par rapport aux années 1976-1980. Pour autant, la Suisse n'arriverait pas à consacrer $0,15 \%$ de son PSB aux pays les plus pauvres. En 1983, le Conseil fédéral a décidé de verser au fonds spécial de l'ONU pour les pays les moins avancés (Fonds PMA) une contribution extraordinaire de 5 millions de francs pour l'année courante. La Suisse souhaite que cet apport aide les pays les plus pauvres à réaliser au moins une partie des programmes et des projets remis en cause par les restrictions apportées au programme du PNUD. 


\section{Sources}

UNCTAD VI, TD/276, Progress in the implementation of the Substantial New Programm of Action for the 1980s for the Least Developped Countries.

CNUCED, TD/B/933, rapport de la deuxième réunion d'institutions d'assistance financière et technique multilatérale et bilatérale et de représentants des pays les moins avancés.

CNUCED, communiqué de presse, TAD/INF/ 1386, 1390, 1438.

Communiqué de presse du DFA, 6 juin 1983.

TA, 28.10.1982.

\subsection{CNUCED VI}

La CNUCED VI s'est déroulée sous le signe d'une crise économique mondiale persistante. Les pays en développement présentèrent leurs doléances selon les documents élaborés à Buenos Aires. Le secrétariat présenta, parmi d'autres, ses plans de programme d'urgence. Les thèmes principaux de la discussion furent les matières premières, le commerce international, les questions financières et monétaires. Après d'âpres pourparlers, on se borna à voter une série de résolutions. Les pays en développement se déclarèrent déçus par l'issue de la conférence. Les pays industriels n'étaient guère enclins à réagir positivement aux nouvelles initiatives qui se faisaient jour. La Suisse s'est surtout montrée préoccupée par le problème des matières premières et par le maintien d'un commerce mondial ouvert.

\subsubsection{La CNUCED VI sous le signe de la crise économique}

La CNUCED VI s'est déroulée sur une toile de fond où dominaient les couleurs de la crise économique que le monde traverse depuis le milieu des années 70. On a constaté dans les pays industriels une stagnation du PNB et un taux élevé de chômage. Les pays en développement souffrent d'un chômage endémique, de la chute du prix des matières premières et de l'accroissement de leur dette extérieure, ces deux derniers phénomènes étant les symptômes essentiels de la crise.

Au cours des années 70, les pays en développement ont pu enregistrer dans l'ensemble une croissance économique moyenne de plus de $5 \%$ par an, de $2,5 \%$ en 1980 , croissance qui était tombée à $0,6 \%$ en 1982 et qui avait fait place en 1982 à un léger recul du $\operatorname{PNB}(0,7 \%)$.

La principale ressource des pays en développement est toujours constituée par la vente des matières premières. Cependant, la part des matières premières dans les recettes globales des pays en développement qui n'exportent pas de pétrole a reculé. Elle ne représente plus que $42 \%$ en 1982. II demeure que 64 pays en développement dépendent à plus de $50 \%$ de la vente de certaines matières premières pour 
leurs rentrées de devises. Les Etats de I'OCDE sont les principaux acheteurs de ces matières premières. Ils rassemblent à eux seuls les deux tiers de la demande. C'est dans ces pays que la demande est stagnante. A un moment où les pays en développement viennent précisément de renforcer leur offre en produits alimentaires comme le café et le cacao ou en boissons tropicales.

Depuis le début des années 80 , les prix des matières premières sont à la baisse. Si les prix réels avaient encore plutôt tendance à monter dans les années 70, ils sont tombés de $13 \%$ en 1981 et encore de $17 \%$ en 1982. En chiffres réels, ils étaient à fin 1982 de moitié plus bas qu'en 1950 à peu près. Une lente progression des prix semble devoir annuler en 1983 la dégringolade enregistrée l'année précédente.

Cette chute du prix des matières premières est l'un des éléments de la crise que connaissent les pays en développement. Baisse des prix et stagnation du volume des exportations engendrent un recul des recettes et une détérioration de la balance des paiements. Afin de pouvoir continuer à financer leurs importations, les pays en développement ont recouru aux crédits publics et privés. Les crédits privés sont consentis à des taux d'intérêt qui dépassent ceux des crédits en fonds publics et pour des durées moindres. Ils aggravent donc d'autant plus l'endettement et ils ont provoqué en maint pays en développement une crise de la dette.

Si la situation économique des pays en développement ne fait qu'empirer, c'est aussi parce que le volume des échanges avec les pays industriels va $s^{\prime}$ amenuisant. La demande de matières premières s'affaiblit, les mesures protectionnistes ruinent les chances des pays pauvres. Circonstance aggravante, les produits finis et autres biens d'importation sont moins demandés et deviennent plus chers.

II en résulte finalement une détérioration des termes de l'échange et une érosion du pouvoir d'achat des pays en développement. La CNUCED estime que, de 1980 à 1982, la chute des prix des matières premières a fait perdre aux pays en développpement 21 milliards de dollars EU.

La crise économique des pays en développement fait baisser leurs importations. Or, le Tiers Monde avait absorbé dans les années 70 une part grandissante des exportations des pays industriels. Pas besoin d'être grand clerc pour en déduire que les imbrications de l'économie universelle répercutent dans les pays industriels les conséquences de la crise éprouvée par les pays en développement. La CNUCED en vient à des pronostics économiques moroses. On ne peut guère espérer un raffermissement durable du prix des matières premières.

$C^{\prime}$ 'est dans ce contexte que se déroulèrent les consultations de la CNUCED VI. Ces conférences de la CNUCED se réunissent tous les quatre 
ans; elles analysent la situation de l'économie mondiale et définissent des stratégies, décrètent des mesures susceptibles de mieux orienter l'effort de développement, de favoriser la coopération internationale économique et financière.

\subsubsection{Préparation de la conférence}

\section{La plate-forme de Buenos Aires}

A sa cinquième réunion mondiale, tenue du 28 mars au 9 avril 1983 à Buenos Aires, le "Groupe des 77" a adopté la "Plate-forme de BuenosAires» qui a constitué la position commune et la stratégie de négociation du groupe pour la CNUCED VI.

La plate-forme consiste en:

un "Message de Buenos Aires, appel au dialogue et au consensus" adopté par les ministres responsables des affaires étrangères et des relations économiques internationales des pays membres du "Groupe des 77" réunis à Buenos Aires;

- une déclaration ministérielle sur la situation de l'économie mondiale;

- une série de déclarations, prises de position et projets de résolutions embrassant l'ensemble des questions à l'ordre du jour provisoire de la Conférence de Belgrade.

Dans leur Message, les ministres s'attachent à réaffirmer la nécessité de mesures intégrées et concertées afin d'en arriver à une restructuration du système économique international. Les ministres expriment leur espoir de voir les pays industrialisés faire eux-mêmes des propositions et prendre position sur les initiatives du "Groupe des 77", de façon à ce que s'instaure un dialogue efficace, conduisant à un accord.

Dans leur déclaration sur les conditions actuelles de l'économie, les ministres du "Groupe des 77" expriment leur volonté de donner plus de moyens aux organismes des Nations Unies susceptibles de coordonner les mesures visant à une reprise de l'activité économique mondiale. Ils constatent le glissement qui s'effectue des négociations multilatérales aux négociations bilatérales. Selon les 77, il est dangereux de vouloir résoudre les graves questions économiques actuelles, en concluant des accords d'Etat à Etat; la concertation doit avoir lieu au sein de la communauté internationale. Et ce d'autant plus que la crise économique n'est pas cyclique; elle repose sur des déséquilibres fondamentaux qui ne peuvent être surmontés que par l'effort commun de tous.

Les 77 démontrent l'interdépendance croissante des différents systèmes économiques, parmi lesquels les pays en développement occupent une place particulièrement délicate. Leur déficit de la balance commerciale durant la période 1980 à 1982 était estimé à 200 mil- 
liards de dollars. La dette extérieure des PVD était estimée à la fin de 1982 à 630 milliards de dollars, avec un service annuel de la dette se montant à 130 milliards de dollars. Parmi les facteurs qui ont contribué à cet état de fait, on trouve des flux de ressources inadéquats, une inflation généralisée, une dégradation des termes de l'échange et une instabilité monétaire prolongée, des taux d'intérêt hauts, les politiques défavorables aux PVD poursuivies par les transnationales et un déséquilibre technologique chronique entre pays industrialisés et pays en développement. En conséquence, le commerce mondial est resté stagnant en 1981 et a baissé de $6 \%$ en termes réels en 1982. Pourtant les PVD sont devenus maintenant un partenaire important dans l'économie internationale; ils absorbent plus de $30 \%$ des exportations des pays industrialisés, et comptent pour $20 \%$ dans la production mondiale.

La stratégie destinée à surmonter la présente crise doit donc reconnaître pleinement le nouveau rôle joué par les PVD, en tant que partenaires de plein droit dans le développement mondial.

Partant de ces constatations, les 77 ont élaboré une série de propositions pour Belgrade, sur chacun des domaines politiques clés, et dans le domaine institutionnel, dont voici quelques-unes parmi les plus importantes:

\section{Produits de base}

Démarrage des opérations du Fonds commun pour les produits de base dès le 1 er janvier 1984.

Arrangements destinés à compenser les déficits des recettes tirées des exportations des pays en développement par:

a) une libéralisation et un élargissement du mécanisme de financement compensatoire du FMI pour permettre une compensation intégrale et automatique de leurs déficits sans conditions. Des arrangements spéciaux pour les pays les moins avancés.

b) Une action des pays socialistes d'Europe orientale, par I'intermédiaire de la Banque internationale d'investissement ou de la Banque internationale de coopération économique, en vue de créer un fonds spécial qui garantisse chaque année un apport suffisant de roubles transférables pour permettre aux PVD de compenser les déficits des recettes qu'ils tirent de l'exportation des produits de base vers les pays socialistes.

\section{Commerce de biens et services}

Levée des mesures protectionnistes contre les exportations des PVD. Formulation d'un programme d'action précis et de durée bien déterminée pour faciliter les aménagements de structure dans ceux des secteurs économiques des pays industrialisés où des mesures protection- 
nistes et des subventions ont pendant de longues périodes été préjudiciables aux intérêts commerciaux des PVD.

Recours au Conseil du commerce et du développement comme mécanisme de coopération dans le domaine des politiques portant sur la production et le commerce.

Amélioration du système généralisé de préférences.

Etudes à réaliser pour le secrétariat de la CNUCED en vue de définir et d'établir des priorités concernant les services présentant une importance particulière pour les PVD et de présenter des recommandations en vue de la création, dans le secteur des services, de mécanismes de coopération multilatérale, comprenant un traitement différencié et plus favorable aux PVD.

Problèmes financiers et monétaires

Renforcement en quantité et en qualité de l'aide publique au développement (APD) et réalisation en 1983 de l'objectif $0,7 \%$ pour l'APD totale et de l'objectif $0,15 \%$ pour I'APD à destination des pays les moins avancés.

Renforcement en quantité et en qualité des ressources du FMI et de la Banque Mondiale disponibles pour les PVD.

Etablissement d'un lien entre DTS et le financement du développement.

Augmentation de la part des PVD dans les quote-parts du FMI en la portant à $45 \%$ du total.

Mise en place d'un nouveau mécanisme pour l'octroi, à des conditions libérales, de ressources financières à moyen terme du FMI aux PVD.

Création d'un nouveau fonds fiduciaire alimenté par les ventes d'or du FMI.

Mesures générales d'urgence destinées à réduire la charge de la dette des PVD, y compris la conversion des prêts d'APD en dons pour les pays les moins avancés et le rééchelonnement des remboursements d'APD pour les autres PVD.

\section{Questions institutionnelles}

Les 77 invitent le Secrétaire général de I'ONU et le Secrétaire général de la CNUCED à prendre des mesures spécifiques sur les points suivants:

- Assurer à la CNUCED la souplesse opérationnelle dans les domaines budgétaire, financier et administratif.

- Déléguer au Secrétaire général de la CNUCED les pouvoirs correspondants, au regard des questions budgétaires et opérationnelles.

- Assurer la coordination avec les commissions régionales et les autres organisations intergouvernementales intéressées.

La plate-forme de Buenos Aires constitue une innovation en ce sens que des projets de résolution sur les points clés de l'ordre du jour ont 
été présentés par les 77 avant le début des négociations à Belgrade. Lors des précédentes sessions de la CNUCED les projets de résolutions avaient généralement été présentés seulement après le début de la session.

Les pays industrialisés ont donc pu prendre position rapidement sur les propositions des 77. C'est ainsi que le Conseil de l'OCDE réuni les 9 et 10 mai 1983 au niveau des ministres s'est exprimé à ce sujet. Les ministres se sont félicités de l'importance attachée à l'interdépendance économique mondiale, au dialogue et au consensus dans les déclarations des PVD, en dernier lieu à Buenos Aires, ils ont déclaré y attacher la même importance. Les ministres ont reconnu que la récession mondiale avait créé de très graves difficultés, en particulier pour la plupart des PVD les plus démunis. Ces derniers, selon les ministres de I'OCDE, ne pourront surmonter ces difficultés qu'en appliquant des politiques sévères et courageuses.

Auparavant, la session spéciale du Conseil du commerce et du développement réunie du 25 au 29 avril 1983 pour accélérer les préparatifs en vue de la CNUCED VI avait fourni aux gouvernements une première occasion de réagir aux propositions que le "Groupe des 77 " allait soumettre à la conférence.

Monsieur Juan Aguirre Lanari, Ministre argentin des affaires étrangères, présentant les résultats de la rencontre ministérielle du "Groupe des 77", rejetait au nom de celui-ci le concept du "filtre" qui considère que le développement serait principalement un sous-produit de la reprise des pays industrialisés, et demandait une série de mesures coordonnées en vue de réactiver l'économie mondiale dans son ensemble.

Monsieur Martin Huslid (Norvège) parlant au nom du "Groupe B» tout entier se félicitait du ton positif et constructif caractérisant le Message de Buenos Aires. Monsieur Huslid acceptait la conclusion des 77 selon laquelle la croissance du pouvoir d'achat et de la capacité d'importation des PVD a joué un rôle capital pour atténuer la gravité de la récession dans les pays développés. Mais parallèlement, l'ensemble contenait, de I'avis du "Groupe B", certaines propositions qui allaient assez loin. Le "Groupe $B$ » voyait ces projets comme des textes qui correspondaient à des positions sur lesquelles les PVD seraient disposés à négocier.

Monsieur Hans Gunter Sulimma (RFA) parlant au nom de la CEE disait apprécier I'appel à la compréhension mutuelle dont témoignait le Message de Buenos Aires. II notait toutefois avec une certaine inquiétude que le texte ne demandait des engagements que d'un groupe, à savoir des pays industrialisés. "Le développement du monde est une responsabilité commune», déclarait-il, "et les mesures concertées devraient être solidaires». Au sujet du commerce, la Communauté réaffirmait 
l'importance qu'elle attachait au maintien d'un système commercial multilatéral et global ouvert à la lutte contre le protectionnisme. Selon la Communauté, le GATT était l'instrument le mieux approprié pour réaliser les objectifs qu'elle poursuivait en ce domaine. La CEE relevait également les tentatives du "Groupe des 77 " d'attribuer la responsabilité des faits négatifs dans le domaine financier et monétaire exclusivement à des facteurs exogènes. De l'avis de la CEE, des politiques améliorées d'ajustement s'imposeraient aussi dans les PVD.

Monsieur Jean-Pierre Maetzler, prenant position au nom de la Suisse, exprimait son appréciation pour la "façon remarquable» dont le "Groupe des 77" avait pu faire avancer les préparatifs pour la conférence, en élaborant des projets de résolution sur les sujets à discuter. Toutefois, il fallait veiller à ce que les solutions envisagées soient réalistes, équitables et tiennent compte des intérêts convergents de tous les pays participants.

Quant à elle, la délégation suisse à la CNUCED VI se félicitait du ton modéré de la déclaration de Buenos Aires, mais se trouvait fort peu convaincue de l'utilité pratique des projets de résolution des 77 . Elle estimait en effet que ceux-ci constituaient simplement la reprise d'une liste de demandes datant déjà de plusieurs années. D'après elle, seule une telle addition de diverses propositions avait permis aux $77 \mathrm{~d}$ 'arriver à un consensus.

\section{Les documents de la CNUCED}

Le secrétariat général de la CNUCED a publié en prévision de la conférence et en conformité avec l'ordre du jour provisoire toute une série de lignes directrices et d'études. Ces documents concernent les objets principaux abordés en cours de conférence, qui sont au nombre de cinq: crise de l'économie mondiale, politique des matières premières, politique commerciale et monétaire, divers. Sans oublier un programme d'urgence et un paquet de mesures à longue échéance pour venir à bout de la crise, si faire se peut.

Dans l'immédiat, il faudra maintenir la capacité d'importation des pays en développement dans une mesure compatible avec leur développement. Le moyen le plus simple pour y parvenir serait d'augmenter leurs recettes à l'exportation. On y arriverait en soutenant les prix des matières premières et en luttant contre le protectionnisme. Une aide financière immédiate améliorerait dans le temps l'efficacité du programme d'aide d'urgence. Le FMI et la Banque mondiale tiennent le rôle principal. Pour les deux années qui viennent, le montant de cette aide financière se situerait autour de 70-90 milliards de dollars. Des accords intérimaires encore à mettre au point stabiliseraient à un prix minimum la valeur de diverses matières premières. 
Pour cette aide financière, I'instrument essentiel du FMI devrait être une augmentation des droits de tirage spéciaux pour les pays en développement, environ 30 milliards de dollars dans les deux années à venir. Il faudrait aussi élever les quotas et permettre au FMI de s'adresser directement au marché des capitaux privés. Quant à la Banque mondiale, le réapprovisionnement de I'AID est aussi urgent qu'une augmentation de son capital.

\subsubsection{Le déroulement de la conférence}

La 6ème session de la CNUCED a eu lieu à Belgrade, du 6 juin au 3 juillet 1983. 148 Etats avaient envoyé des délégations sur les $166 \mathrm{mem}$ bres de la CNUCED. Plus de 60 organisations des Nations Unies et d'autres institutions intergouvernementales prirent en outre part à ces entretiens.

Les travaux de la conférence ont occupé les débats de l'assemblée plénière et de quatre grandes commissions. L'assemblée plénière s'est occupée de la situation de l'économie mondiale et des résultats obtenus avec le "Nouveau programme substantiel d'action" pour les pays les plus pauvres. Les quatre commissions principales traitèrent les thèmes suivants:

- matières premières;

- questions financières et monétaires;

- activités de la CNUCED en différents domaines (relations commerciales, transfert de technologie, navigation maritime, relations commerciales entre le Sud et l'Est et entre pays du Sud, coopération économique entre pays en développement).

Lors de la dernière semaine de la conférence, le ministre des affaires étrangères yougoslave Lazar Mojsov, président de la conférence, forma un groupe restreint chargé de mieux coordonner les travaux des divers comités. On retrouvait là les ministres de neuf pays en développement, de cinq nations occidentales, de trois pays du bloc de l'Est et de la Chine. Des coordonnateurs régionaux vinrent se joindre à eux. On pense pouvoir faire redémarrer ainsi des négociations arrivées au point mort.

Les négociations de la CNUCED VI ont été dominées par le "Groupe des 77" (125 pays en développement) et par le "Groupe B" (pays de $\mathrm{I}^{\prime} \mathrm{OCDE}$ ). Les pays à commerce étatisé $n^{\prime}$ ont guère joué un rôle actif lors des débats, alors que la Chine se présentait en tant que membre individuel de la CNUCED. Par ailleurs, les pays en développement formèrent des groupes régionaux: africain, asiatique, latino-américain.

Le "Groupe des 77" s'était bien préparé et avait décidé de s'en tenir à ce qu'on appelle la plate-forme de Buenos Aires. Il parvint à s'en tenir à 
cette stratégie collective durant toute la durée de la conférence. Les pays membres du «Groupe $B$ » n'entamèrent pas de négociations préparatoires. La plupart de ses membres pensent que la CNUCED est la clé du dialogue Nord-Sud, mais certains autres Etats estiment que les institutions issues des accords de Bretton Woods gardent la priorité. Les EU ont joué un rôle peu coopératif lors de la CNUCED VI et se sont cantonnés dans l'opposition durant le plus clair des négociations. Ils ont refusé de se joindre à diverses déclarations finales. En dépit de l'opinion qui s'était manifestée au début des débats, aucune "déclaration de Belgrade" ne fut publiée par les participants. Le programme d'urgence souhaité par le secrétariat général ne fut pas non plus adopté. La conférence fut prolongée et ne parvint à admettre qu'une série de résolutions ne contenant aucune mesure concrète en faveur des pays en développement. L'étude de certaines propositions se poursuivra au sein de divers comités de la CNUCED.

Le porte-parole du "Groupe des 77", dans une déclaration finale, exprimait que la conférence avait été un événement historique. En choisissant la plate-forme de Buenos Aires comme préalable de la conférence, le "Groupe des 77" espérait provoquer les réponses des pays industriels. Pour cela, il fallut attendre la fin des débats. Les pays en développement avaient espéré que la conférence déboucherait sur des résultats positifs, notamment en ce qui concerne:

une amélioration du transfert réel des ressources dans les pays en développement;

- la prise en charge de flux financiers substantiels dans les pays en développement;

- l'ouverture des marchés des pays industriels aux exportations des pays en développement;

- des mesures susceptibles d'empêcher à l'avenir la chute rapide du prix des matières premières;

- l'amorce d'une restructuration des institutions internationales;

- des réformes structurelles dans les pays industriels.

La conférence s'est terminěe avec un résultat minime. Dans le domaine des matières premières, elle a confirmé les positions connues et n'a fait que peu de progrès.

Pour le commerce international, les propositions devaient être envisagées dans le cadre de structures inamovibles. C'est sur le plan financier et monétaire qu'il aurait fallu agir d'urgence. Les pays en développement ont tout de même décidé d'accepter les résolutions finales et de concentrer leurs efforts sur les négociations à venir.

Le porte-parole du "Groupe B» estima que la déclaration du «Groupe des 77" était par trop critique. Les résolutions de la conférence fournissent la base de travaux ultérieurs. Les résultats sont satisfaisants et on ne saurait nullement parler d'échec. 


\subsubsection{Les thèmes et les résultats de la conférence}

\section{Matières premières}

Une commission de la conférence avait à étudier les questions touchant aux matières premières. On trouvait à l'ordre du jour:

- examen de la situation dans le secteur matières premières;

- utilisation du programme intégré des matières premières;

- fonds de stabilisation des recettes d'exportation;

- transformation, commercialisation et distribution des matières premières.

Le secrétariat général a publié un guide qui renvoie au programme intégré des matières premières adopté à la CNUCED IV de Nairobi, en 1976, et il propose une ratification aussi rapide que possible du Fonds commun pour les produits de base. Pour le reste, il faudrait procéder à l'évaluation des accords existants et en conclure de nouveaux, sur $d$ 'autres matières premières. De nouveaux accords devraient entrer en vigueur à titre provisoire dans le cadre du programme urgent pour la stabisation des prix et des recettes d'exportation; les accords existants devraient être renforcés. Ils devraient être financés par les fonds spéciaux du FMI pour les stocks compensatoires de matières premières et par les programmes de crédits pour les réformes de structures de la Banque mondiale et des banques régionales de développement. Pour stabiliser les recettes d'exportation actuelles, le FMI devrait améliorer son mécanisme de financement et tenir compte des pays à économie planifiée. A longue échéance, il y a lieu de mettre en place un mécanisme de stabilisation des exportations, les pays occidentaux devront ouvrir leurs marchés et les pays de l'Est européen devront se procurer dans les pays en développement davantage de matières premières et de produits finis. Pour faciliter la transformation et la commercialisation des matières premières, il y aurait lieu $d^{\prime}$ accorder aux pays en développement une aide financière et technique et d'améliorer la transparence des marchés. Toutes ces mesures doivent largement tenir compte des besoins des pays les plus pauvres.

Lors des négociations, le "Groupe des 77 » mit l'accent sur les mesures visant à augmenter la part prise par les pays en développement à la transformation, la commercialisation et la distribution des matières premières. II insista aussi sur la nécessité de renforcer à bref délai la facilité financière du FMI et de créer une facilité supplémentaire des recettes d'exportation.

Les pays en développement placent en première priorité l'entrée en vigueur du programme intégré des matières premières. Cinq nouveaux pays ont ratifié l'accord sur le Fonds commun pour les produits de base et 16 l'ont signé. Dans le domaine de la transformation, les Etats de I'OCDE n'ont pas de conception globale, ils se prononcent pour une 
expertise spécifique dans chaque cas et une participation plus élevée des investissements directs venant de l'étranger. Un groupe d'experts devrait être constitué pour discuter d'une facilité de stabilisation des recettes d'exportation.

Dans sa résolution finale sur les questions touchant aux matières premières, la conférence dit s'attendre à l'entrée en vigueur du Fonds commun pour les produits de base au 1er janvier 1984; elle se prononce en faveur de la conclusion d'un nouvel accord international sur le blé. Un système nouveau de coopération internationale devrait être créé pour la transformation, la commercialisation et la distribution des exportations de matières premières. Le FMI doit revoir sa facilité de stabilisation des recettes d'exportation. Un groupe d'experts de la CNUCED doit en outre étudier la nécessité d'une nouvelle facilité et, le cas échéant, en définir les mécanismes.

\section{Commerce et protectionnisme}

La deuxième commission avait à débattre du commerce international des marchandises et services, du protectionnisme et de la réforme des structures, de l'examen des structures du commerce international en considération de la situation actuelle, des mesures à prendre pour favoriser le commerce et le développement.

Dans le document de synthèse, le secrétariat général de la CNUCED analyse les formes actuelles du protectionnisme, expose quels sont les instruments de la politique commerciale internationale et les raisons des mesures de caractère protectionniste; il indique enfin comment des réformes de structures peuvent contribuer à un meilleur fonctionnement du commerce mondial. Le quatrième volet dégage certaines conclusions en termes concrets et énonce des recommandations.

Quant au renforcement du commerce international et à la réforme des structures, le secrétariat propose:

- au niveau national, de renforcer le contrôle des mesures protectionnistes, de prendre des mesures pour modifier les structures;

- au niveau international, de définir les critères auxquels on se référera dans les différentes situations où l'on recourra à des mesures protectionnistes, de soumettre la politique commerciale et économique nationale à des études et échanges d'information.

La résolution finale de la CNUCED VI conclut ainsi ce qu'elle consacre au thème "commerce international des marchandises et services":

- le protectionnisme fait obstacle au commerce international et au développement. Les pays industriels s'entêtent au maintien des actuelles mesures protectionnistes dirigées contre les importations en provenance du Tiers Monde. Ils atténuent les restrictions commerciales tarifaires ou non tarifaires selon le rythme de la reprise économique. Les clauses de protection doivent être révisées dans le 
cadre du GATT. Finalement, la libéralisation du commerce mondial et la réforme des structures se conditionnent mutuellement et favorisent un essor économique universel;

- le Conseil de la CNUCED examine l'état du système commercial international et fait des propositions. Les pays industriels doivent simplifier leurs systèmes de préférences douanières et continuer d'en faire profiter unilatéralement les pays en développement, quoi qu'il arrive. II n'y a pas lieu d'exiger des pays en développement qu'ils ouvrent leurs marchés en conséquence;

- la CNUCED peut décider de nouvelles études sur le rôle des services dans le processus de développement et sur l'importance qu'ils revêtent pour les moins avancés des pays en développement. Les EtatsUnis n'ont pas voté ce passage de la résolution, car ils estiment que ce serait au GATT de s'occuper de cette question.

\section{Finances et monnaies}

La troisième commission de la CNUCED s'est penchée sur les problèmes financiers et monétaires: questions financières et monétaires en relation avec le commerce et le développement; augmentation et amélioration des flux financiers dirigés vers les pays en développement et équilibre des balances des paiements.

Le secrétariat général de la CNUCED avait proposé comme base des travaux de cette commission le rapport sur les "Questions financières et monétaires internationales". Ce document place au centre de l'analyse les répercussions négatives des difficultés de l'économie mondiale sur les balances des paiements des pays en développement; il propose dans l'immédiat trois mesures à prendre pour combattre la récession et pour ranimer le commerce des pays en développement:

- l'augmentation des flux financiers publics et privés pour un volume d'environ 70 milliards de dollars EU au cours des deux prochaines années et aux meilleures conditions. Cette augmentation de leurs liquidités permettrait aux pays en développement de réduire le poids du service de la dette;

- les pays en développement doivent faire apparaître davantage de rentrées en devises de leurs relations commerciales avec l'étranger; d'autre part, ils doivent économiser les devises et améliorer le niveau des investissements chez eux. C'est de cette manière qu'ils iront vers un équilibre de leur balance commerciale;

- les pays industriels ont pour leur part à combiner leur politique de lutte contre l'inflation avec des mesures susceptibles de diminuer le chômage, de faire baisser les taux d'intérêt et de mettre fin au protectionnisme.

Pour augmenter les flux financiers en fonds publics au cours des deux années qui viennent, le FMI doit créer de nouveaux droits de tirages spéciaux, augmenter les quotas et la part que les pays en développe- 
ment prennent à ces quotas, et par des ventes d'or mettre de nouvelles ressources financières à la disposition des pays en développement. II faut modifier les conditions d'octroi des crédits du FMI, afin de mieux tenir compte des objectifs du développement. La Banque mondiale doit augmenter le volume de ses prêts et assumer le septième réapprovisionnement de I'AID.

Dans le domaine de la coopération publique au développement, il s'agirait au cours des deux années qui viennent de transformer en dons les crédits accordés aux pays les plus pauvres pour leur développement. On réitère la demande adressée aux pays industriels de consacrer aux dépenses pour le développement 0,7\% de leur PNB; ce taux devrait être atteint en 1985, au plus tard en 1990.

Les négociations de la commission commencèrent lentement et se terminèrent sans résultats appréciables. On a notamment débattu d'une proposition visant à convoquer une conférence monétaire internationale spéciale. On a fini par s'accorder sur une résolution finale à propos des "questions monétaires internationales», dont les principales recommandations s'énoncent ainsi :

création d'un système financier et monétaire international stable; le Conseil exécutif du FMI doit étudier l'élévation des droits de tirage spéciaux, comme le problème de l'augmentation des quotas et $\mathrm{d}^{\prime}$ autres possibilités de financement qui comptent beaucoup pour les pays en développement. Concernant les conditions d'octroi des crédits, on veillera surtout à stimuler la demande et à fortifier la production;

- quant à l'endettement des pays en développement, les pays industriels étudieront une consolidation des dettes publiques. En règle générale, on doit combiner la consolidation des dettes avec des programmes de relance. Les pays industriels ont également pris l'engagement de porter à $0,7 \%$ du PSB et au plus tard en 1990 la part consacrée à l'aide au développement ou tout au moins de redoubler d'efforts dans ce but.

\section{Autres activités de la CNUCED}

La quatrième commission avait à traiter de toute une série d'autres activités de la CNUCED telle que problèmes de la technologie, navigation, commerce Sud-Sud et Sud-Est, difficultés de développement des Etats insulaires ou sans débouché sur la mer, soutien accordé à des organisations de libération nationale. Le secrétariat général avait préparé une documentation de base sur toutes ces questions. Les résolutions finales qui ont été votées permettront à la CNUCED de s'occuper plus énergiquement du transfert de technologie. On a surtout discuté de la commercialisation des produits pharmaceutiques, un des domaines qui retiennent le plus I'attention de I'OMS. 
Le "Groupe B» ne voudrait pas que la CNUCED en fasse autant à l'ave nir dans ces domaines et pense qu'il serait judicieux de coordonner les travaux avec les autres organisations de l'ONU. Dans les autres domai. nes, la conférence accepta des propositions à porter au programme de travail des comités compétents de la CNUCED. La majorité du «Groupe $B$ " a qualifié de résolutions politiques la surveillance exercée par la CNUCED sur la situation en Palestine et en Afrique du Sud (Namibie). La CNUCED n'est pas le forum idéal pour ce genre d'exercices, c'est pourquoi cette majorité n'a pas voté les résolutions proposées, les EU votant, eux, contre.

En cours de conférence, un groupe de travail se forma pour étudier l'un des thèmes traités en assemblée plénière: "Situation actuelle de l'économie internationale»; il ne parvint guère à rapprocher pays en développement et pays industriels quant à l'analyse et aux mesures à prendre. Les EU rejetèrent I'analyse présentée et divers pays industriels occidentaux firent savoir qu'ils ne partageaient pas toutes les opinions émises dans la résolution.

La conférence prit acte des progrès réalisés en faveur des pays les plus pauvres à l'enseigne du "Nouveau programme substantiel d'action». Elle recommanda une fois de plus aux pays donateurs de consacrer $0,15 \%$ de leur PNB à l'aide aux pays les moins avancés, objectif à atteindre en 1985. Ou pour le moins doubler le plus vite possible l'aide fournie.

\subsubsection{L'attitude de la Suisse à la conférence}

La délégation suisse à la CNUCED était dirigée par l'ambassadeur Eric Röthlisberger, délégué du Conseil fédéral aux accords commerciaux. Le conseiller fédéral Furgler prit la parole au cours du débat général.

La Suisse est d'avis que la CNUCED représente un nouveau pas en avant dans le dialogue Nord-Sud. Le conseiller fédéral Furgler souhaita voir s'installer un climat de travail faisant place à l'équité, au réalisme, à I'initiative et à la confiance. II relève que I'indispensable bond en avant ne se ferait que si le Nord et le Sud tiraient tous les deux à la même corde. Les propositions concrètes que ne manquerait pas de formuler la conférence devraient tenir compte des possibiltés économiques, car tout se joue dans un espace économique amenuisé par le chômage et les restrictions budgétaires.

La Suisse attache de l'importance à la stabilisation des marchés des matières premières, au maintien d'un système ouvert d'échanges commerciaux dans le monde, à l'abolition du protectionnisme et à l'intégration en termes juridiques des pays en développement dans le commerce mondial. Notre pays appuie les efforts des pays en développement pour améliorer les échanges entre pays du Sud et se prononce 
pour une augmentation à court terme du transfert des ressources, notamment des montants finançant les accords généraux d'emprunt du FMI. La Suisse se déclare disposée à augmenter le volume de sa coopération au développement en fonds publics, notamment en faveur des pays les moins avancés.

Membre du "Groupe B", la Suisse eut à faire face dans les quatre commissions aux exigences des pays en développement. Elle émit l'opinion que la CNUCED ne trahit nullement sa mission quand elle lie le problème des matières premières et les difficultés du développement. La Suisse refusa pourtant de s'associer à un vaste programme de mesures urgentes. Dans le domaine des matières premières, elle se prononce pour la mise en œuvre du Programme intégré et pour que les matières premières soient plus souvent transformées dans les pays en développement eux-mêmes. La Suisse suggéra également qu'on s'interroge sur l'utilité de la création d'une nouvelle facilité des revenus d'exportation.

En ce qui concerne le commerce des marchandises et des services, la Suisse se déclara en faveur d'une démobilisation des mesures protectionnistes et pour une plus grande sécurité juridique des pays en développement appelés à bénéficier peu à peu de tous les droits du GATT et à en assumer tous les devoirs.

Quant au domaine des finances internationales et des monnaies, la Suisse donna à entendre qu'elle coopérait désormais plus étroitement avec le $\mathrm{FMI}$, la première des institutions spécialisées en ces matières. N'étant membres ni du FMI ni de la Banque mondiale, notre pays n'a pris aucune initiative particulière. II reste cependant persuadé qu'il est nécessaire de fortifier les institutions multilatérales qui financent le développement. Pour assainir les finances des pays endettés, il conviendrait de recourir à des solutions propres à chacun d'eux. La Suisse estime en outre qu'il faut augmenter le transfert des ressources privées et publiques, les pays les moins avancés méritant à cet égard une attention particulière.

Dans les considérations finales sur les diverses résolutions, la Suisse regretta que ni l'analyse de la situation économique internationale ni l'énoncé des mesures arrêtées pour l'améliorer n'aient permis de dégager des vues communes. Elle n'était pas d'accord avec tous les points de la résolution finale et $s^{\prime}$ abstint de voter pour ou contre les résolutions politiques sur le Liban et l'Afrique du Sud.

Les organisations non gouvernementales de Suisse furent consultées à l'époque où notre délégation se préparait à la conférence. Ces consultations ne furent pas portées à la connaissance du public. Le comité "Pain pour le prochain" exprima le vœu de voir la Suisse apporter à la conférence une contribution originale, même s'il lui fallait s'opposer aux autres pays industriels. La Suisse devrait viser à l'avènement d'un 
ordre économique mondial ouvert et honnête et le faire tant par solidarité qu'en considération de ses propres intérêts à long terme.

La Fédération genevoise de coopération en appela au Conseil fédéral avant l'ouverture de la conférence. Elle proposait que la délégation se prononçât clairement pour des mesures de stabilisation des prix, comprenant entre autres la création du Fonds commun des matières premières. La FGC souhaite aussi voir maintenues les mesures d'expansion commerciale en faveur des pays les moins avancés, ainsi que les négociations sur les finances et les monnaies.

\section{Sources}

UNCTAD VI, The Buenos Aires Platform, Belgrade, June 1983.

CNUCED, TD 271-281, documents directifs CNUCED VI.

CNUCED, Communiqués de presse TAD/INF 1459-1492.

CNUCED-Bulletin, No 193, mai 1983.

ifda/ips, Special United Nations Service 775-810, Nyon/Rome.

Le Monde, 2, 3, 4, 5.7.1983.

\section{UNESCO}

\subsection{Seconde conférence sur les politiques culturelles de I'UNESCO (Mondiacult)}

Cette conférence, la seconde après celle de Venise en 1970, s'est tenue du 26 juillet au 5 août 1982, conformément à la résolution qui avait été adoptée par la Conférence générale de l'UNESCO à Belgrade, lors de sa 21 ème session (voir Annuaire Suisse-Tiers Monde 1982, pp. 127 et suivantes). Son but était de faire le bilan des années parcourues après la rencontre de Venise, et de rechercher de nouvelles perspectives de collaboration internationale dans le domaine de la culture. Les représentants de 126 Etats membres ont participé à la Conférence.

Les politiques et pratiques culturelles ont été au centre des discussions; il s'agissait de susciter une réflexion approfondie sur les problèmes fondamentaux de la culture dans le monde contemporain, et de formuler des orientations nouvelles propres à renforcer la dimension culturelle du développement général et à faciliter la coopération culturelle internationale.

La Conférence a clos ses travaux en adoptant à I'unanimité la "Déclaration de Mexico sur les politiques culturelles", ainsi qu'un nombre élevé de recommandations, soit 181. La Déclaration dégage la définition suivante de la culture: $D^{\prime}$ après le document final, "dans son sens le plus large, la culture peut aujourd'hui être considérée comme l'ensemble des traits distinctifs, spirituels et matériels, intellectuels et 
affectifs, qui caractérisent une société ou un groupe social. Elle englobe, outre les arts et les lettres, les modes de vie, les droits fondamentaux de l'être humain, les systèmes de valeurs, les traditions et les croyances". La Déclaration met entre autres l'accent sur la nécessité de veiller à préserver et à défendre l'identité culturelle de chaque peuple, sur la nécessaire restitution à leurs pays d'origine des œuvres qui leur ont été retirées de façon illicite. Selon la Déclaration, les moyens de communication modernes doivent faciliter l'information objective sur les tendances culturelles qui peuvent être observées dans les différents pays, sans pour autant porter préjudice à la liberté créatrice et à l'identité culturelle des nations. La Déclaration ne contient pas d'appel à la constitution d'un nouvel ordre mondial de l'information, comme l'avaient souhaité certains pays du Tiers Monde; le principe de I'unanimité n'a pas permis devant l'opposition des pays occidentaux de fair passer une telle résolution.

La délégation suisse, menée par l'ambassadeur Ernesto Thalmann, président de la Commission nationale suisse pour I'UNESCO, était composée en outre de $M$. Frédéric Dubois, directeur de l'Office fédéral de la culture, de I'ambassadeur Charles Hummel, délégué permanent de la Suisse auprès de I'UNESCO. Tout au long de la Conférence, la délégation suisse s'est rangée résolument aux côtés de celles des autres pays industrialisés.

L'ambassadeur Thalmann, dans son discours devant la Conférence, cité par UNESCO Presse, a mis en évidence le rôle de la politique culturelle comme un des fondements de la politique sociale et de la politique de développement. L'ambassadeur a mentionné l'initiative fédérale sur la culture, qui vise à l'introduction d'un nouvel article constitutionnel faisant obligation à la Confédération d'appuyer la production culturelle helvétique par le biais de subsides, facilités administratives et autres. Mais il a également insisté sur la nécessité d'un respect du fédéralisme et de la diversité culturelle. "En Suisse, chaque canton, chaque ville, chaque commune dirige sa propre politique culturelle, dont les buts sont fixés par l'ensemble de la population. [...] Les interventions de l'Etat doivent être strictement limitées, car ce n'est pas l'Etat qui fait la culture.»

De manière générale, la Suisse a constamment recherché des applications concrètes aux idées fondamentales des documents utilisés, principalement en ce qui concerne le dialogue entre les cultures et ses problèmes, ainsi que l'intégration de la science et de la technique dans la culture. Trois recommandations suisses furent adoptées par la Conférence. La première concerne les arts populaires traditionnels et le tourisme, et recommande au Directeur général d'inclure dans le prochain programme biennal de I'UNESCO I'organisation d'une réunion internationale sur le thème "Folklore et tourisme». La seconde traite de la coexistence des différents groupes culturels dans un Etat et leurs rela- 
tions avec l'étranger, et recommande aux Etats membres de considérer que la coexistence de tels groupes est un facteur d'équilibre et que la manifestation de leur identité propre est compatible avec leur identification à l'Etat; celui-ci, ainsi que les membres de la communauté étatique, doivent reconnaître les valeurs culturelles de chaque groupe; l'appartenance de tout individu à son propre groupe culturel est inhérente à sa dignité. Enfin, une troisième recommandation propose le développement des échanges culturels internationaux, par le biais d'un renforcement du rôle de I'UNESCO, et d'une intensification de ses activités dans ce domaine.

\section{Sources}

Rapport final de la Conférence mondiale sur les politiques culturelles à Mexico, 26 juillet.

6 août 1982, Paris, UNESCO, 1982, 211 pages et annexes.

UNESCO Presse, Service de presse de la Commission nationale suisse pour I'UNESCO, septembre-octobre 1982, juillet-août 1982.

\subsection{4ème session extraordinaire de la Conférence générale de I'UNESCO}

Cette conférence, qui s'est tenue à Paris du 29 novembre au 3 décembre 1982, avait à l'ordre du jour l'examen d'un projet de plan à moyen terme, définissant les orientations que I'UNESCO compte adopter jusqu'à la fin de la décennie et se composant de 14 grands programmes à mettre en œuvre dans les domaines d'activités de l'Organisation.

Ce plan a été élaboré sur la base des directives énoncées par la Conférence générale à la 21 ème session et après consultation du Conseil exécutif. II s'inspire très largement des résultats de la consultation des Etats membres, des membres associés et des organisations internationales gouvernementales et non gouvernementales et de nombreuses personnalités, qui a été menée au cours du premier semestre de l'année 1981.

De manière générale, cette conférence a été une nouvelle occasion de voir exposées les deux orientations assez distinctes que présentent d'une part les pays industrialisés, les pays en développement d'autre part: les pays du Nord sont traditionnellement très attachés à la notion individuelle de culture, d'information et d'éducation, toute véritable démocratie culturelle passant à leurs yeux d'abord par le respect des droits individuels de l'homme. Les pays du Sud, quant à eux, conçoivent l'ensemble de ces domaines comme étant subordonnés à la construction de la société, de l'économie, de la Nation. Ces divergences philosophiques ne doivent toutefois pas faire oublier les enjeux très directement commerciaux qu'impliquent certains choix. Les médias, les agences de presse, les fournisseurs de matériel de communication occidentaux sont directement intéressés à la circulation totalement 
libre de leurs produits, qui, bien entendu, véhiculent des valeurs culturelles fondamentalement différentes de celles que connaissent les pays du Sud.

Cette session extraordinaire se justifiait par la volonté de mener une analyse des problèmes dès le stade initial de la planification, afin que le choix de domaines prioritaires puisse être guidé par une appréciation concrète des situations et des problèmes, au lieu d'être en quelque sorte prédéterminé par l'existence de programmes en cours. Autrement dit, à l'issue du plan 1977-1982, il s'agissait de reprendre une étude générale de la situation dans laquelle I'UNESCO doit intervenir, et de présenter devant les membres de nouvelles propositions et de nouvelles orientations.

Les quatorze programmes adoptés sont les suivants:

1 Réflexion sur les problèmes mondiaux et études prospectives.

2 L'éducation pour tous.

3 La communication au service de tous.

4 Conception et mise en œuvre des politiques de l'éducation.

5 Education, formation et société.

6 Les sciences et leur application au développement.

7 Systèmes d'information et accès à la connaissance.

8 Principes, méthodes et stratégies de l'action pour le développement.

9 Science, technologie et société.

10 Environnement humain et ressources terrestres et maritimes.

11 La culture et I'avenir.

12 Elimination des préjugés, de l'intolérance, du racisme et de l'apartheid.

13 Paix, compréhension internationale, droits de I'homme et droits des peuples.

14 La condition des femmes.

Les oppositions se sont une nouvelle fois cristallisées lors de cette conférence autour de la notion de communication au service de l'homme. En effet, cette question, qui touche directement au principe du Nouvel ordre mondial de l'information souhaité par les pays du Tiers Monde, voyait à nouveau les pays industrialisés prôner la liberté totale du flux d'information, s'opposant ainsi aux pays du Sud qui voulaient écarter la dépendance presque totale des pays en développement à l'égard des pays du Nord, pour ce qui concerne les médias.

La délégation suisse à la conférence était constituée de l'ambassadeur Ernesto Thalmann, président de la commission nationale suisse pour I'UNESCO, chef de la délégation, de l'ambassadeur Charles Hummel, représentant permanent de la Suisse auprès de I'UNESCO, et de M. Frédéric Dubois, directeur de I'Office fédéral de la culture. La Suisse a pris lors de cette conférence des positions très tranchées, de sorte 
qu'il est possible de donner un aperçu des moments forts de la session en faisant le résumé des activités de sa délégation.

Le chef de la délégation, l'ambassadeur Ernesto Thalmann, intervenait déjà au second jour de la conférence pour présenter des critiques importantes à l'Organisation et à son directeur: I'ambassadeur Thalmann commençait par affirmer qu'en Suisse "l'intérêt voué à l'Organisation a tendance à diminuer. L'UNESCO des projets concrets, utiles et réussis fait moins parler d'elle que I'UNESCO des controverses stériles». II poursuivait en donnant sa définition des buts que I'UNESCO devrait poursuivre. L'organistion doit servir I'homme et non pas ses idéologies. II est faux "de vouloir rejeter la responsabilité des grands problèmes existants sur un seul groupe de pays». L'UNESCO ne doit pas s'attacher à faire de longues déclarations sur le désarmement et la paix, mais doit tenter très concrètement de "permettre à chaque individu de jouir plus complètement de la paix, de la justice, du droit et plus particulièrement des droits de I'homme». L'ambassadeur Thalmann exprimait aussi l'inquiétude générale de la Suisse que puissent disparaître les droits de l'individu devant ceux de la collectivité.

Ce discours fut suivi d'une protestation immédiate du directeur général, Amadou Mahtar M'Bow, qui prenait ainsi quelque liberté avec le protocole. M'Bow s'estimait personnellement attaqué, il réfutait le reproche d'une analyse idéologiquement unilatérale de la situation mondiale et tenait pour infondée la crainte de voir disparaître les libertés individuelles des préoccupations de l'Organisation. De manière générale, $M^{\prime} B o w$ estimait que le texte présenté avait été mal interprété. La délégation suisse a renoncé à faire suivre l'intervention de M'Bow d'une duplique. Le discours de l'ambassadeur Thalmann a reçu en coulisse l'approbation des délégués des pays industrialisés.

Le Conseil exécutif avait mis en place les mécanismes destinés à l'examen du plan: une plénière destinée à couvrir le débat général et pour ainsi dire tous les points controversés des programmes, et deux commissions de programme, dont la seconde fut présidée par l'ambassadeur Hummel, affectées à une discussion plus détaillée des autres parties du plan. Le programme sur la communication fut le seul point critiqué mis à l'ordre du jour d'une commission (la première). Cette organisation de la conférence avait suscité I'opposition de la RFA devant le Conseil exécutif; elle n'avait pas l'assentiment de la plupart des pays industrialisés. Les textes initiaux ne faisant pas l'unanimité, il aurait été loisible au directeur général de s'appuyer sur sa majorité quasiautomatique auprès des pays du Sud pour les faire voter malgré tout; mais I'image de I'UNESCO auprès des pays industrialisés et les moyens de financement de l'Organisation en auraient été fortement compromis.

Pour débloquer les négociations qui menaçaient de déboucher sur une scission des participants en deux blocs: à nouveau et presque tradi- 
tionnellement le Nord contre le Sud, le groupe africain prit l'initiative de proposer la formation d'un groupe de rédaction ad hoc, qui fut effectivement créé, avec l'accord et l'appui du directeur général. Ce groupe, dont firent partie, pour les pays occidentaux, la Suisse, les Etats-Unis, la RFA et la France, réussit en deux jours et deux nuits à passer en revue les points de divergence des 14 chapitres du Plan, et à trouver des formules qui puissent recueillir une approbation unanime des participants. La présidence de ce groupe fut confiée au Sénégalais Iba Der Thiam, également président de la Commission I. La Suisse put à cette occasion orienter de façon non négligeable les textes vers une conception des droits de I'homme plus proche de ses thèses.

Les grands programmes concernant l'éducation rencontrèrent des avis largement positifs. L'accent fut mis sur la poursuite du combat contre l'analphabétisme, également sous ses formes secondaires ou techniques. De nombreuses interventions avaient pour objet la formation professionnelle technique, à laquelle les Etats attachent toujours plus d'importance.

Les grands programmes concernant les sciences donnèrent à la délégation suisse l'occasion de mettre l'accent sur la formation, l'échange d'informations et la vulgarisation scientifique, tâches essentielles de I'UNESCO dans le domaine des sciences. Les nouveaux domaines d'intérêt de l'UNESCO, particulièrement celui de l'environnement, ont été approuvés par l'ensemble des pays membres.

La culture, qui faisait l'objet d'un autre grand programme, n'occupa pas une place prédominante dans les discussions, principalement du fait des résolutions récentes qui avaient été prises lors de Mondiacult à Mexico, en été 1982, et qui avaient été l'occasion de mener un débat de fond sur le sujet.

II fut finalement possible de trouver un compromis satisfaisant dans le domaine des programmes "Paix, désarmement et droits de I'homme». II s'agissait principalement pour la Suisse d'éviter que la notion de désarmement et de paix prenne une place trop importante face aux droits de I'homme, ceux-ci, selon la Suisse, sont primordiaux. De leur côté, les pays du Tiers Monde réussirent à faire inscrire la notion de "droits des peuples" plutôt que de "liberté des peuples", malgré la réticence des pays occidentaux. Quant au «droit de la communication», la Suisse a déposé une explication de vote qui le place en relation directe avec la liberté d'expression et d'opinion, telle que définie dans la Déclaration universelle des droits de I'homme de 1948.

Mais le domaine le plus important et le plus controversé abordé pendant cette conférence reste celui de la communication et de l'information. Les pays du Tiers Monde persistaient à considérer comme inadmissible le déséquilibre dû au quasi-monopole des organes d'information occidentaux dans les pays du Sud. Les pays du Nord, eux, 
tenaient à sauvegarder absolument le principe de la liberté des médias.

Finalement la résolution votée réaffirmait la nécessité d'un nouvel équilibre et d'une meilleure réciprocité dans la circulation de l'information, ainsi que d'une correction des inégalités dans la circulation de l'information à destination et en provenance des pays en développement ainsi qu'entre ces pays. Mais la résolution affirme également que les journalistes doivent être vigilants face aux abus de pouvoir commis à l'égard des médias.

En ce qui concerne les ressources de l'UNESCO, la résolution adoptée, contre les voix de la Suisse et de plusieurs autres pays occidentaux, prévoit un taux de croissance global réel des ressources de 4 à $6 \%$; il faut toutefois noter que le texte se trouve nettement en retrait de la proposition du "Groupe des 77", qui souhaitait une progression fixe de $6 \%$.

\section{Sources}

Actes de la Conférence générale, 4ème session extraordinaire, Résolutions et Deuxième plan à moyen terme (1984-1989), Paris, UNESCO, 1983.

NZZ, Tribune le Matin, Tagesanzeiger, novembre/décembre 1982.

\section{CONFERENCE DE L'ONU SUR LE DROIT DE LA MER}

Les travaux en vue de l'entrée en vigueur de la convention de l'ONU sur le droit de la mer continuent de progresser. On note cependant des réticences de la part des Etats-Unis et de quelques pays industriels européens. La Suisse reste dans I'expectative.

C'est à Montego Bay (Jamaïque), du 6 au 10 décembre 1982, qu'a eu lieu la dernière réunion de la Ille conférence des Nations Unies sur le droit de la mer en présence des représentants de 144 Etats. Réunion réservée à la signature de la convention sur le droit de la mer dont le texte avait été arrêté en mars 1982.

A cette occasion, la convention a été signée par 119 délégations (117 Etats, ainsi que les îles Cook et le conseil de l'ONU pour la Namibie). Vingt-trois Etats, dont les Etats-Unis et plusieurs pays européens, contresignèrent le document final, mais pas la convention. A fin avril 1983, la convention avait été signée par 125 Etats, mais 5 seulement I'avaient déjà ratifiée. Se prononcent à ce jour en faveur de la convention la plupart des pays en développement, les pays à économie planifiée et quelques pays industriels.

La convention entre formellement en vigueur un an après avoir été ratifiée par 60 Etats signataires au moins. Le délai de ratification est de deux ans pour chaque pays signataire. La commission préparatoire prévue par la conférence a commencé ses travaux en mars 1983, à la Jamaïque. Elle établira les règlements à la disposition de l'autorité des 
fonds marins et du tribunal de la mer; elle enregistrera les premiers investissements et le nom de leurs auteurs.

L'importance historique de la convention réside dans l'application du droit international à l'exploitation de la mer (navigation maritime, environnement, minerais des grands fonds). La conclusion de cet accord est l'un des succès les plus significatifs remportés par le système de I'ONU depuis sa création; elle représente pour les pays en développement un pas en avant vers le nouvel ordre économique mondial qu'ils souhaitent voir s'établir. Le fait que les Etats-Unis soient restés sur la touche depuis les débuts de l'ère Reagan en diminue beaucoup la portée pratique. L'accord obtenu est même remis en question en l'absence d'une coopération avec les Etats-Unis, le pays disposant de la technologie de pointe pour l'exploitation des minerais des grands fonds. D'autres pays industriels se tiennent également sur la réserve. Une inquiétude d'ordre politique $s^{\prime} y$ fait jour et inspire des critiques contre la réglementation quelque peu autoritaire de l'activité minière sur les fonds marins. Ces pays espèrent que la convention subira diverses modifications au cours des travaux de la commission préparatoire.

A la Jamaïque, la Suisse $\mathrm{n}^{\prime}$ a pas signé la convention, tout en portant sur elle un jugement fort positif. Malgré ses réserves d'ordre politique, notre pays envisage de signer la convention plus tard et de la ratifier par la suite. Avant de franchir le pas, la Suisse observera le comportement des autres pays industriels. Le Conseil fédéral attend de voir ce que donneront les négociations entre pays industriels et les travaux de la commission préparatoire. La Suisse voue une attention particulière à la réglementation de la navigation. Le Conseil fédéral préfère dans l'ensemble une réglementation contraignante en droit international à un vide juridique où les Etats riverains feraient prévaloir l'arbitraire. La Suisse attache beaucoup d'importance aux droits de transit des bateaux et des aéronefs; elle estime que sa situation de pays sans accès à la mer s'en trouve améliorée.

En mars 1983, I'administrtion Reagan fit savoir qu'elle ne participerait pas à la convention et elle mit unilatéralement en vigueur diverses dispositions (zone de protection économique de 200 milles). Entre-temps, les représentants des pays industriels intéressés continuent de débattre, en dehors des travaux de la conférence de I'ONU, d'une réglementation de l'extraction des minerais des fonds marins. Ces pays (EtatsUnis, RFA, France, Grande-Bretagne) parviendront-ils à imposer leur projet au plan politique? On peut en douter.

\section{Sources}

20ème rapport sur le commerce extérieur, 12 janvier 1953, pp. 53 et suivantes. 
Nations Unies 1/1983, p. 27.

NZZ, 12.7., 10-13.12.1982, 3.1.1983.

South, août, novembre 1982 .

i3m-actualités 3/1983.

\section{CONFERENCE DE L'OMPI SUR LA REVISION DU DROIT INTERNATIONAL DES BREVETS}

La troisième session n'a pu poursuivre la révision que sur quelques points. Les pays industriels sont parvenus à faire admettre un réexamen du compromis de Nairobi. La Suisse apprécie fort qu'on veuille protéger le droit de la propriété industrielle, mais est disposée à entrer dans les vues des pays en développement.

C'est du 4 au 29 octobre à Genève qu'a eu lieu la première partie de la troisième session de la conférence sur le droit international des brevets, la seconde partie se déroulant du 23 au 27 novembre. Etaient présentes les délégations de 79 pays, dont 62 seulement étaient membres de la Convention de Paris.

La conférence a pour but d'adapter à la situation économique et technologique des pays en développement les dispositions sur la protection nominale des brevets, modèles et marques, et celles qui concernent la lutte contre la concurrence déloyale. Un renforcement des sanctions favoriserait l'exploitation industrielle des inventions brevetées dans les pays en développement.

La révision prévue souligne certaines innovations à introduire dans le droit des brevets. Alors que les fournisseurs de technologie mettaient jusqu'ici l'accent sur la protection des droits de monopole du détenteur du brevet, les pays en développement se préoccupent surtout de l'exploitation artisanale et industrielle des brevets.

La base de la révision est un travail d'experts déjà fort élaboré et datant de 1975. Ce texte prévoit des contraintes dans l'exploitation des brevets et des sanctions accrues sous forme de licences non volontaires exclusives ou de caducité du brevet en cas d'exploitation délaissée ou insuffisante.

La deuxième session tenue à Nairobi en octobre 1981 avait prévu que les pays en développement auraient la possibilité d'introduire des licences forcées; à l'issue de cette session, les représentants de l'industrie des EU, d'Europe et du Japon tinrent une "Inter-Industry-Conference" qui en vint à remettre en question et à redéfinir la révision tout juste adoptée. Dans l'intervalle des sessions, les EU annoncèrent leur intention de ne pas ratifier la révision proposée.

Les pays industriels espèrent que la conférence renoncera à l'octroi de licences forcées décidé à Nairobi et qu'on révisera la procédure accélé- 
rée de déclaration de caducité des brevets. Ils sont prêts à consentir aux pays en développement le recours facultatif à la protection juridique des procédés (article 5 quater) pour les biens d'importation.

\section{Les négociations de la troisième session}

Au début de la troisième session, il n'a pas été question des licences forcées si discutées. L'ordre du jour portait sur:

- la parité du certificat d'invention et du brevet d'invention (article 1);

- la protection du nom des Etats contre l'enregistrement et l'usage en tant que marque (article 6 ter);

- la protection des données sur l'origine géographique (article 10 quater).

Durant la première partie de la session, un article 6 ter révisé a été accepté, les articles 1 et 10 quater ont été étudiés. En marge de la session, un groupe de liaison s'est entretenu d'une redéfinition du compromis élaboré à Nairobi.

Convoquée de manière surprenante, la deuxième partie de la session a été entièrement consacrée à un réexamen du compromis de Nairobi sur l'introduction de licences non volontaires exclusives (article $5 \mathrm{~A}$ ) et la question de la protection des procédés de fabrication (article 5 quater). Aucune entente n'a pu être réalisée.

Un groupe restreint de représentants de 10 pays industriels et de pays en développement présenta un nouveau projet qui ne tient plus compte de l'octroi de licences non volontaires exclusives. Selon ce texte, les pays en développement seraient dispensés d'appliquer l'article 5 quater.

Convoquée par une réunion ad hoc, une quatrième session poursuivra les négociations. On se retrouvera donc du 27 février au 24 mars 1984 à Genève.

\section{L'attitude de la Suisse}

Comme ce fut le cas lors des sessions précédentes, le chef de la délégation suisse, Paul Brändli, directeur de l'Office fédéral de la propriété intellectuelle, était aussi le porte-parole du groupe des pays industriels. De cette façon, la délégation suisse occupait une position-clé au cours des négociations.

Une interpellation Auer (PR/BL) prie le Conseil fédéral «de prendre position face aux résultats obtenus lors de la deuxième ronde des négociations et de préciser sur quelles bases la Suisse entend négocier". Dans sa réponse écrite du 6 décembre 1982, le Conseil fédéral reste fort réservé, afin de ne pas compromettre sa position lors des négociations. Certaines inquiétudes soulevées par l'interpellation ont été dissipées entre-temps par l'amorce d'une révision du compromis de Nairobi. En ligne générale, le Conseil fédéral souligne qu'il attache 
beaucoup de prix à la protection de la propriété industrielle pour notre économie. Le but de la révision est cependant "à la fois de donner satisfaction aux justes prétentions des pays en développement et de partir du point de vue qu'il y a lieu de protéger et de maintenir le niveau de vie des pays industriels. Le Conseil fédéral ne présentera pas à l'agrément des Chambres une version révisée de la Convention de Paris qui mettrait en péril les intérêts vitaux de notre pays".

Comme l'écrit le Conseil fédéral, aucune négociation sur l'article $5 \mathrm{~A}$ n'a eu lieu devant les organes officiels de la conférence au cours de la troisième session. A l'initiative des EU, un groupe de liaison s'est formé dans l'intention de remodeler le compromis de Nairobi. En faisaient partie dix personnalités, dont le chef de la délégation suisse. $\mathrm{Ce}$ groupe de liaison a présenté à la conférence un programme en trois points:

- supprimer les licences non volontaires exclusives accordées aux pays en développement;

- clarifier les conditions de caducité et de retrait des brevets;

- dispenser les pays en développement d'appliquer l'article 5 quater concernant les brevets sur les processus de fabrication.

Lors de ces tentatives de conciliation, la Suisse s'est montrée très active; le programme en trois points constitue la nouvelle base des négociations.

En Suisse même, le Vorort a attiré l'attention sur l'intérêt qu'il y avait pour notre pays à maintenir un haut niveau de protection pour les brevets d'invention. Sinon, le développement et la recherche en Suisse pourraient être compromis. Si la conférence doit aboutir à une protection insuffisante des brevets, le Vorort se demande si la Suisse devrait rester membre de la Convention de Paris et si elle devrait accepter le nouvel accord; aux yeux du Vorort, de lourdes responsabilités incombent à la délégation du gouvernement suisse et il y aurait lieu de renégocier le compromis de Nairobi.

Les pays industriels souhaitent un compromis sur le caractère purement facultatif de la protection des procédés de fabrication; cette disposition touche aux produits d'importation; le Vorort pense qu'elle constitue une mesure de protection essentielle pour l'industrie chimique.

La communauté de travail des œuvres d'entraide Swissaid/Action de Carême/Pain pour le prochain/Helvetas a exprimé, à propos de cette troisième session, la crainte que la Suisse ne tienne guère compte de la politique de développement dans son approche de la révision en cours; la communauté de travail demande au Conseil fédéral de tout mettre en œuvre pour que les négociations actuelles "se terminent de façon conforme aux intérêts de la politique de développement». N'oublions pas qu'au temps de notre propre industrialisation, diverses branches 
industrielles ont combattu durant des décennies l'introduction d'un droit de brevet et même un niveau élevé de protection.

\section{Sources}

OMPI, rapport d'activité pour 1982 .

OMPI, communiqué de presse no 20-24, 1982.

Conseil fédéral, 82.547, interpellation Auer du 4 octobre 1982.

Union suisse du commerce et de l'industrie, Vorort, rapport annuel 19811982.

NZZ, 5-7-12-26-30/31.10; 26-29.11; 15.12.1982.

Der Bund, 10 janvier 1982.

\section{4ème COMMISSION DE L'ONU SUR LES SOCIETES TRANSNATIONALES - CODE DE CONDUITE}

Rien de moins certain que la mise au point de ce code. Les dernières négociations n'ont nullement permis de définir les sociétés transnationales (STN) ni la manière dont devaient les traiter les gouvernements qui les accueillent. On ne sait quelle attitude adopter face aux STN des pays à commerce étatisé. Incertitude concernant la poursuite des pourparlers. La Suisse souhaite qu'on parvienne à mettre ce code au point.

La commission de l'ONU sur les sociétés transnationales travaille depuis 1977 à mettre au point un code de conduite à l'usage des sociétés transnationales. A ce jour, les deux tiers du texte prévu sont disponibles. Aucun consensus n'a pu cependant s'établir entre les pays en développement, les pays industriels occidentaux et les pays à économie planifiée en ce qui concerne la deuxième partie du code "Traitement des STN par les pays d'accueil».

Lors des négociations précédentes, un accord assez complet a pu se faire sur la première partie du code intitulée "Comportement des sociétés transnationales dans les pays d'accueil». Les sociétés transnationales doivent s'engager à respecter les droits de l'homme, les libertés fondamentales ainsi que la souveraineté nationale, les lois et l'identité culturelle du pays d'accueil. Le texte réglemente également la politique commerciale des sociétés transnationales en ce qui concerne la transparence, la taxation fiscale, le transfert des bénéfices et les prix de transfert.

On n'est pas encore parvenu à déterminer formellement la nature juridique du code, mais ce document devrait sans doute avoir en droit un caractère non coercitif. Son efficacité serait renforcée par un système de surveillance. Dans l'état actuel des négociations, cette définition controversée garde toute son importance. Les pays industriels estiment qu'un code n'incluant pas les pays à économie planifiée n'est politiquement pas recevable. 


\section{Les dernières négociations}

Lors de la 8 ème réunion de la commission de l'ONU sur les sociétés transnationales (Manille, 30 août - 10 septembre 1982), on a souligné une fois de plus que priorité devait être reconnue à la mise au point du code et que les négociations devraient pouvoir connaître une heureuse issue dans le délai d'un an. Le porte-parole des pays en développement affirma que toutes les entreprises transnationales, sans égard pour la domiciliation de leur siège principal, devraient tomber sous la juridiction du code. Dans l'optique des pays en développement, leurs propres transnationales et aussi celles des pays à économie planifiée seraient ainsi soumises au code.

Lors de cette réunion, les travaux du groupe de travail intergouvernemental chargé de la remise des pouvoirs furent menés à leur terme. Au cours du premier semestre de 1983, la commission a repris les négociations en son nom et cela durant une session extraordinaire de quatre semaines ouverte à tous les Etats.

La première partie de cette session (du 7 au 18 mars 1983) fut dominée par la discussion concernant la définition du terme société transnationale. Les pays industriels sont d'avis, opinion apparemment partagée par les pays en développement, que toutes les entreprises qui travaillent en deux pays ou plus doivent être qualifiées de transnationales. A cette condition, le code aurait une portée universelle. Les pays à économie dirigée se prononcent pour le moment contre la soumission au code de leurs entreprises travaillant au plan international.

Au cours de la seconde partie de la réunion (du 9 au 21 mai), on a surtout parlé des règles de conduite à adopter par les pays d'accueil. Aucun accord n'a pu se faire quant au degré de droit international coutumier qu'il convenait d'introduire dans le code. Les pays industriels se réfèrent aux normes établies et toujours valables. Les pays en développement veulent qu'en chaque occasion leurs tribunaux statuent selon de droit national. En cas d'éventuelles nationalisations et d'indemnisations ultérieures, la question du droit applicable est extrêmement importante. A ce chapitre, on n'est pas non plus parvenu à statuer, à la demande des pays industriels, sur l'égalité de traitement entre les entreprises étrangères et indigènes dans le pays $d$ 'accueil.

Le président mexicain de la session a présenté un "texte de compromis" en fait de définition, texte qui a emporté l'assentiment du "Groupe des 77" et du "Groupe D». Ces deux groupes ont cependant refusé de se prononcer sur les demandes de précisions souhaitées par les pays industriels occidentaux. Sous sa forme actuelle, la définition ne peut en aucun cas être admise par les pays industriels.

$C^{\prime}$ est en mai également qu'un petit groupe informel de négociation a présenté une proposition de texte qui devrait régler la conduite des 
sociétés transnationales en Afrique du Sud et en Namibie. A ce jour, les pays en développement avaient exigé un arrêt et même un retrait des investissements. On demande maintenant aux entreprises transnationales de mettre un terme à toutes les activités susceptibles de consolider le régime d'apartheid et l'occupation illégale de la Namibie. Dans la mesure de leurs possibilités, elles devraient plutôt s'efforcer d'écarter le régime d'apartheid et se confirmer aux conclusions du Conseil de sécurité de l'ONU sur I'Afrique du Sud. Selon une recommandation du Conseil de sécurité (283/1970), les investissements des entreprises étatisées devraient être retirés de Namibie et les investissements privés également. Les délégations ont demandé un temps de réflexion avant de se prononcer sur cette proposition.

Le Conseil économique et social de I'ONU n'est même pas parvenu, au cours de sa réunion annuelle estivale de cette année (du 6 au 27 juillet, à Genève) à renouveler le mandat de la commission, bien que tous les groupes régionaux se fussent prononcés pour la continuation des négociations. II incombera à l'assemblée générale de I'ONU de se prononcer en automne sur la reprise des négociations.

\section{L'attitude de la Suisse}

Représentée par l'ambassadeur Lévy, la Suisse a participé aux négociations depuis le début. Elle s'est chargée du rôle de coordonnateur pour le groupe des pays de l'OCDE. Le caractère malaisé des négociations ne l'empêche pas de garder un intérêt intact à ce code en gestation; notre pays espère qu'on aboutira bientôt. II estime que le code peut jouer un rôle de premier plan dans la création et le maintien de bonnes relations entre pays d'accueil, notamment pays en développement, et les investisseurs étrangers. La présence d'un climat favorable aux investissements est également en jeu. La Suisse s'intéresse au libre transfert de la technologie et de l'investissement.

\section{Sources}

Chronique de I'ONU, novembre 1982.

ONU, communiqué de presse, TNC/31, 23.5.1983.

NZZ, 27-31.8., 17.9.1982, 18.3., 24.5., 1.7.1983.

\section{TRANSFERT DE TECHNOLOGIE: COMMISSION DE L'ONU ET COMITE DE LA CNUCED}

Les travaux du comité intérimaire de l'ONU n'ont guère permis de rapprocher les positions prises par les négociateurs. La discussion est singulièrement vive sur les pratiques commerciales restrictives et le droit applicable. La CNUCED se prononce pour une "décommercialisation» limitée des transferts de technologie. 
C'est en 1976, lors de la CNUCED IV, à Nairobi, que fut décidée la création d'un code de conduite. Bien préparée, la conférence de l'ONU sur un code de conduite en matière de transferts de technologie se réunit depuis 1978. On s'est d'abord mis d'accord sur des questions ne prêtant pas à controverse. Depuis 1981, la conférence a piétiné du fait des fortes divergences d'opinion opposant sur les objets importants les pays industriels, les pays en développement et les pays à économie planifiée.

L'assemblée générale de l'ONU décida en 1981 de confier à un comité intérimaire la solution des difficultés qui subsistaient. On souhaitait accélérer le rythme des travaux. Le comité intérimaire devait examiner les problèmes en suspens et formuler des propositions à l'attention de la 5ème session de la conférence. Au cours de 1982, le comité intérimaire se réunit à trois reprises, la durée totale de ses travaux s'étendant à quatre semaines; la 5ème session de la conférence aura lieu en octobre 1983.

A l'issue des travaux du comité intérimaire, on peut constater que les positions des 90 Etats représentés ne sont guère plus rapprochées qu'au début. La nature juridique du code devrait être basée sur des engagements non coercitifs, au moins jusqu'à la première révision, cinq ans après la mise au point du texte initial. Dans l'état actuel des négociations, il ne semble guère que l'entente puisse se faire sur les chapitres 4 et 9 .

Le chapitre 4 concerne les pratiques commerciales restrictives; c'est la pierre d'achoppement des négociations. Au départ, les pays en développement étaient d'avis que les fournisseurs de technologie devraient renoncer totalement aux clauses restrictives à l'intention des utilisateurs de licences, par exemple les interdictions d'exportations et les limitations de prix. Les pays industriels ne veulent reconnaître pour nuisibles que les clauses gênant par trop la concurrence.

A ce chapitre, l'interprétation des règles de conduite à adopter pour les transferts de technologie internes aux multinationales est fort controversée. Les pays industriels ne veulent pas entendre parler de restrictions dans ce domaine. Les pays en développement insistent pour que de tels transferts de technologie soient soumis au code, vu que ce qui se transmet à titre interne dans les multinationales représente une grande part de tous les transferts de techologie.

On n'a pu se mettre d'accord sur le degré de responsabilité des parties en cause (chapitre 5). Ni sur le droit applicable et l'arbitrage des différends (chapitre 9). Dans I'optique des pays en développement, c'est le droit de la nation où la technologie est appliquée qui prime et un tribunal arbitral ne peut être saisi qu'avec l'accord du pays en développement. Les pays industriels se prononcent pour le libre choix de la juridiction. 
Singulièrement importantes pour la Suisse, ces négociations autour des chapitres 4 et 9 du projet de code. Reconnaître le droit à la libre concurrence équivaut à faire un pas en direction des pays en développement. Considérées comme des pratiques commerciales restrictives, certaines obligations contractuelles lui semblent cependant raisonnables. Elles permettent entre autres de maintenir la qualité d'un produit. Quant au droit applicable, la Suisse se prononce pour le maintien de procédures de conciliation.

\section{Comité de la CNUCED pour le transfert de technologie}

C'est au comité de la CNUCED pour le transfert de technologie que se déroulent les négociations sur la stratégie applicable au transfert de technologie vers les pays en développement. Lors de la 4ème session de ce comité (29 novembre - 12 décembre 1982), le secrétariat de la CNUCED présenta un rapport sur la stratégie des mutations technologiques dans les pays en développement. Aux yeux du secrétariat de la CNUCED, cette stratégie est I'un des éléments du "Nouvel ordre économique mondial» auquel on espère parvenir. Son aspect essentiel est la "décommercialisation" de la technologie qui est mise au point et exploitée grâce à des subventions étatiques.

Lors de la même session, l'organisation de consommateurs IOCU présenta un projet de code de conduite pour l'industrie pharmaceutique. Ce texte a été établi par l'organisation non-gouvernementale HAl. II vise à mettre à la disposition des consommateurs des médicaments sûrs et efficaces à des prix accessibles. Selon elle, il y a lieu de réduire la publicité, les campagnes RP, le nombre des représentants des entreprises pharmaceutiques et l'on devrait pousser la production nationale de médicaments.

\section{Sources}

CNUCED, communiqués de presse TAD/INF 1382, 1385.

UNCTAD-TD/277, UNCTAD VI - A strategy for technological transformation of developing countries.

CNUCED-TD/CODE TOT/35: Rapport du comité intérimaire de la conférence des Nations Unies sur un code international pour le transfert de technologie. NZZ, 5.10.1982; 3.1.1983.

epd-entwicklungspolitik 1/1983.

\section{SEMINAIRE DE L'ONU SUR LE ROLE DES SOCIETES TRANSNATIONALES EN AFRIQUE DU SUD ET EN NAMIBIE}

Ce séminaire, qui devait se tenir les 1 er et 2 juillet 1982 à Genève, a finalement été reporté aux 8 et 9 novembre 1982. Quatrième du genre à se tenir dans un pays de siège des sociétés transnationales qui opèrent en Afrique du 
Sud, ce séminaire était la conséquence de la résolution 35/28 de l'Assemblée générale de l'ONU, datant de novembre 1980, et qui fut adoptée contre les voix des Etats occidentaux.

L'organisation en était confiée à la Division de l'information économi que et sociale du Département de I'information publique des Nations Unies, en association avec le Centre des Nations Unies sur les sociétés transnationales et le Centre des Nations Unies contre l'apartheid.

Le séminaire de Genève a rassemblé des membres des médias ainsi que des syndicalistes, des représentants d'organisations non gouvernementales, des universités et des groupes d'entreprises notamment de la République fédérale d'Allemagne et de la Suisse.

Rapidement, le séminaire a fait l'objet d'une vive opposition de la part des milieux d'affaires, qui accusaient les organisations de vouloir, sous le label de I'ONU, mener une cabale contre les entreprises multinationales. Ils critiquaient particulièrement le Conseil œcuménique des Eglises, un des invités du séminaire, pour avoir, affirmaient-ils, menacé de quitter celui-ci. Le COE exigeait, selon eux, que deux études ne correspondant pas à ses vues soient retirées, puisqu'elles approuvaient les investissements des multinationales en Afrique du Sud, rompant donc par là l'unité de vue supposée des participants. Le COE publia une mise au point selon laquelle son désir avait été de repousser encore une fois la date d'ouverture, étant donné que seules les deux études en question étaient disponibles, ce qui n'était, aux yeux du COE, ni correct, ni suffisant.

Ces deux documents furent finalement présentés, et la conférence put suivre son cours, sans toutefois qu'on puisse affirmer qu'elle ait permis une large information du public à propos des problèmes traités.

Les nombreuses études présentées, tant sur les relations de I'Allemagne que de la Suisse avec l'Afrique du Sud, proposaient des analyses économiques et politiques parfois fort différentes. Les différentes options peuvent être résumées ainsi :

- Développement économique intensifié, qui produira automatique ment un changement politique (thèse Oppenheimer, du nom du grand industriel sud-africain), c'est-à-dire susciter des investissements importants et diversifiés, favorisant un fort taux de croissance économique, de sorte que, en dernier ressort, la population africaine sera totalement intégrée, économiquement et politiquement.

- Poursuivre les contacts mais en les utilisant comme un instrument de changement politique et social; c'est-à-dire faire en sorte que toutes les activités publiques et privées sur lesquelles on a une influence soient orientées vers un tel changement.

- Désengagement, ou désinvestissement, qui consisterait, par des mesures volontaires des entreprises ou par décision des Etats ayant 
des relations avec l'Afrique du Sud, à dissuader les partenaires commerciaux de poursuivre leurs échanges.

- Pressions exercées par les gouvernements occidentaux sur le gouvernement sud-africain, en usant de moyens économiques; dans ce cas, les Etats occidentaux, par des mesures économiques actives, telles que l'interdiction de commerce avec l'Afrique du Sud, tenteraient d'infléchir les positions du gouvernement sud-africain.

- Sanctions globales; celles-ci pourraient consister en la rupture de toutes relations économiques, culturelles, sportives, politiques ou autres, sous forme d'un blocus généralisé.

On peut affirmer que la thèse Oppenheimer prévaut encore dans les entreprises transnationaleslorsqu'ils'agit de justifier leur présence en Afrique du Sud. II existe des codes de conduite qui tentent de faire appliquer une politique plus rigoureuse par les industriels et les investisseurs; ces codes réfutent en principe la ségrégation raciale et tentent de fixer des salaires minimaux; $d$ 'autre part ils veulent favoriser la formation professionnelle des Africains, et leur insertion plus réelle dans la vie économique sud-africaine. En bref, le but est d'atteindre à l'égalité entre tous les travailleurs. La tentative la plus intéressante de ce point de vue est sans doute le Code de conduite pour les sociétés possédant des succursales, des entreprises ou représentations en Afrique du Sud, édicté par la CEE, et approuvé par les ministres des affaires étrangères des neuf le 20 septembre 1977; I'application du Code et le contrôle sont laissés à l'initiative de chaque Etat.

Aux Etats-Unis, les principes de Sullivan, du nom du pastęur instigateur de ce texte, ont été repris par certaines entreprises; l'adhésion est toujours volontaire et elle $n^{\prime}$ a aucun caractère officiel. Ce code est le plus avancé qui soit appliqué par les entreprises nord-américaines; il est proche de celui de la CEE.

Les partisans d'un retrait massif et le plus rapide possible des investissements d'Afrique du Sud considèrent que toute amélioration apparente du statut des travailleurs africains ne fait que perpétuer un système social condamnable parce qu'essentiellement oppresseur. Le South African Congress of Trade Unions, qui reste un des plus puissants groupements syndicaux africains en Afrique du Sud, défend cette politique. L'argumentation des partisans du désengagement est fondée sur deux thèses: d'une part la pratique "progressiste" des transnationales n'est qu'un paravent pour calmer les opinions publiques occidentales; lorsque le besoin s'en fait sentir, les entreprises recourent à la violence policière et étatique; le SACTU cite des exemples de grèves ainsi brisées. D'autre part, l'évolution de la législation et la poursuite, sinon le renforcement, de la politique de "développement séparé", c'est-à-dire la création de bantoustans jouant le rôle de réservoirs de main-d'œuvre, prouvent que la situation ne peut évoluer que par des mesures drastiques. 
Les partisans de la poursuite de la collaboration avec I'Afrique du Sud ont su allier des critères moraux à des arguments politiques et économiques évidents, qui font qu'ils emportent I'appui non seulement des entreprises, ce qui va de soi, mais également des gouvernements occidentaux.

En effet, I'Afrique du Sud est un marché non négligeable; plus encore, elle offre des conditions de production, eu égard particulièrement au niveau très bas des salaires, qui sont fort attractives. La position stratégique de l'Afrique du Sud est importante, son emplacement géographique lui permet le contrôle des voies maritimes de I'Atlantique Sud et de I'Océan Indien. Les Etats africains n'ayant exercé jusqu'à aujourd'hui aucune pression véritable sur les pays occidentaux pour qu'ils cessent leurs relations avec la République sud-africaine, force est de constater qu'il y a conjonction d'intérêts rendant non seulement inutile mais carrément dommageable aux yeux des transnationales et des gouvernements tout désengagement dans les conditions actuelles.

\section{Les relations Suisse - Afrique du Sud}

L'espace économique namibien est compris de fait dans celui de l'Afrique du Sud, il y sera donc assimilé ici, quoique le statut politique des habitants de la Namibie soit différent de celui des Noirs d'Afrique du Sud.

Si I'on examine rapidement la nature des relations économiques qu'entretient la Suisse avec l'Afrique du Sud, on constate qu'en 1981, un quart de la dette extérieure des banques sud-africaines était contractée auprès de banques suisses. Une grande partie de l'or sudafricain transite par la place financière de Zurich, qui tenait en 1981 $40 \%$ du marché mondial. La Suisse était en 1981 le quatrième partenaire de l'Afrique du Sud en ce qui concerne les exportations, et le septième au regard de ses importations. La Suisse importe entre autres des fruits, de la viande, du charbon, des diamants, du platine et de l'or d'Afrique du Sud. 54 entreprises suisses sont représentées en Afrique du Sud, qui en contrôlent plus de 70 sud-africaines.

Deux courants contradictoires se sont trouvés confrontés lors du séminaire de Genève: I'un, plutôt favorable aux investissements suisses en Afrique du Sud, était représenté par Mme Bettina S. Hürni (Hürni, 1983), I'autre, opposé à toute relation avec I'Afrique du Sud, était défendu dans les documents présentés par le Mouvement antiapartheid de Suisse.

\section{L'intérêt de la présence helvétique en Afrique du Sud}

Mme Hürni estime que les conclusions de la Commission Wiehahn (formée par le gouvernement sud-africain après les émeutes de Soweto en 
1976) ont eu une influence décisive dans le processus de libéralisation du droit ségrégationniste appliqué. De même, l'utilité des codes mis en vigueur par des compagnies transnationales, tels les principes Sullivan, est certaine. On prouve ainsi que les entreprises peuvent influencer le gouvernement. Le Conseil sud-africain des Eglises a également édicté un code qui a été adopté par les entreprises suisses en Afrique du Sud. La pratique de celles-ci est plus libérale que les termes du code; les Suisses ont été les premiers à introduire des cantines mixtes; ils paient des salaires deux à cinq fois supérieurs au minimum légal; ils ont créé de nombreuses écoles techniques mixtes.

La pénurie de main-d'œuvre qualifiée, malgré la situation économique dorénavant moins florissante, ne peut être que profitable à la majorité noire. C'est dans ce contexte que Mme Hürni veut analyser les activités des entreprises suisses en Afrique du Sud.

Les différences de salaire entre Blancs et Noirs sont considérées comme étant un problème social: les Noirs sont sous-qualifiés, et par conséquent moins bien payés. Les entreprises suisses s'attachent à former leurs employés noirs, pour combler le fossé. Les entreprises suisses ont entrepris d'elles-mêmes la création de comités de liaison où siègent des travailleurs africains. Mme Hürni constate que la loi sudafricaine impose certaines limites, par exemple un Noir n'a pas le droit $d^{\prime}$ accéder à un poste supérieur à celui d'un Blanc et les conventions collectives sont toujours négociées par le biais des "Conseils industriels", qui ne reconnaissent que les syndicats officiels. Dans I'ensemble, les progrès sont longs à réaliser, mais substantiels.

Mme Hürni estime que la concertation et la persuasion doivent être utilisées pour éviter le danger de troubles sociaux. Les entreprises suisses utilisent ces moyens avec succès, principalement parce que leur taille est plus faible que celle d'autres firmes, étrangères. Le boycott économique $n^{\prime}$ a jamais encore mené à un changement politique positif et paisible. Le gouvernement sud-africain est en train d'assouplir sa position, et les sociétés transnationales (STN) peuvent certainement amener des changements positifs. Celles-ci doivent supporter la pleine responsabilité de leurs actions, et c'est pourquoi elles peuvent être fières de leur engagement social, et de leur succès dans ce domaine.

\section{L'avis du Mouvement anti-apartheid}

Les documents présentés par le Mouvement anti-apartheid de Suisse prennent bien entendu le contre-pied de l'analyse exposée plus haut. Les auteurs s'accordent tous sur l'importance, eu égard aux dimensions de la Suisse, des relations économiques entre cette dernière et I'Afrique du Sud; mais depuis les années 70 les exportations suisses vers le Nigéria, l'Algérie, la Libye et l'Egypte se sont considérablement développées, et l'Afrique du Sud n'absorbe plus que le quart des 
exportations vers I'Afrique. Ces pays ont pris des positions militaires contre l'apartheid et c'est plutôt d'eux que dépend aujourd'hui la conservation des places de travail de l'industrie d'exportation suisse.

En ce qui concerne les activités de STN d'origine suisse en Afrique du Sud, le document affirme que ces dernières ont un intérêt à utiliser une main-d'œuvre qualifiée et stable, du fait de leur spécialisation dans les industries de transformation, à capital intensif. Il est toutefois évident que les STN suisses s'accommodent bien du système légal d'apartheid, même si elles s'appliquent à le rendre moins voyant. De plus, les réactions en cas de troubles sociaux peuvent être fort brutales. L'Alusaf, dont $22 \%$ du capital est aux mains d'Alusuisse et qui se fournit exclusivement auprès de cette entreprise, a congédié 1.700 grévistes après un arrêt de travail décidé le 15 juin 1982. La police est intervenue massivement; il y a eu plusieurs blessés graves et neuf «meneurs» ont été arrêtés. Cet événement ne peut être considéré, selon le Mouvement anti-apartheid, comme unique. Enfin, affirme ce dernier, la Suisse joue un rôle non négligeable dans les fournitures de matériel et de combustible nucléaire à l'A frique du Sud. La société Kaiseraugst SA a vendu à la fin de l'année 1981 une certaine quantité de combustible, quoique par des intermédiaires, à l'Afrique du Sud, à destination de la centrale de Koeberg.

\section{Sources}

Ansprenger Franz, Activities in the Republic of South Africa of Transnational Corporations which have their Headquarters in the Federal Republic of Germany, document présenté au Séminaire de Genève.

Gaetsewe John, La condition des travailleurs dans les sociétés transnationales d'Afrique du Sud, document présenté au Séminaire de Genève.

Mesures prises par l'Organisation des Nations Unies pour empêcher la collaboration des sociétés transnationales avec I'Afrique du Sud, document d'information No 8 au Séminaire de Genève.

Hürni Bettina, Les activités en Afrique du Sud des sociétés transnationales ayant leur siège en Suisse, Genève, Société pour le développement de l'économie suisse, Bulletin de documentation économique, No 1, janvier 1983. NZZ, 18,19.9.1982.

Mouvement anti-apartheid de Suisse, Le rôle des multinationales en Afrique du Sud: commentaire socio-politique, Henri Stauffer, Marianne Laufer, JeanPierre Lagnaux.

\section{SEPTIEME CONFERENCE DES PAYS NON ALIGNES}

Cette conférence a réuni du 7 au 11 mars 1983, sous la présidence de Indira Gandhi, premier ministre de l'Inde, plus de 130 délégations; $80 \%$ des Etats membres des Nations Unies s'y retrouvent à titre d'adhérents, d'observateurs 
et d'invités. Le mouvement représente 1,7 milliards d'habitants de plus de cent pays adhérents.

Le non alignement, né dans les années 50 du rapprochement d'une poignée de chefs d'Etats tels que Jawaharlal Nehru, Josip Tito, Gamal Abdel Nasser et Ahmed Soekarno, a vu le nombre de ses adhérents quadrupler en vingt ans. De tout temps, les dissensions politiques ont été nombreuses et régulièrement certains prédisaient la fin du mouvement. II n'en a rien été, et cela est largement dû au fait qu'au-delà des divergences, la nécessité de jouir d'un organe de contact commun pour les pays du Sud, leur permettant d'occuper une position un peu plus solide face aux pays industrialisés, s'est toujours fait sentir. Mais l'ambiance et le style ont bien changé, et aucun des fondateurs du mouvement n'était plus présent à cette conférence de New Dehli. Josip Tito était décédé quelque temps après le sommet de la Havane de 1979.

Aujourd'hui, le mouvement des non-alignés s'identifie avec de nombreuses initiatives issues de pays du Tiers Monde, et particulièrement à I'ONU. II est I'inspirateur du "Groupe des 77" qui a joué un rôle considérable dans la création et le développement d'organismes tels que la CNUCED, ou encore I'ONUDI. Le concept de Nouvel ordre économique international a trouvé ses bases lors de la 4ème conférence des chefs d'Etats et de gouvernements de 1973. Les non-alignés sont directement intéressés à la création d'un Nouvel ordre international de l'information.

Le 6ème sommet qui s'est tenu en 1979 à la Havane avait ravivé certaines inquiétudes de ce point de vue lorsque le chef de l'Etat cubain Fidel Castro avait défendu devant la conférence le point de vue selon lequel I'URSS et en général les pays du COMECON étaient les alliés naturels du mouvement des non-alignés, étant donné leurs prises de position résolument anti-impérialistes. Les réactions d'un certain nombre de membres avaient été fort mitigées, vu les liens qui étaient les leurs avec les pays occidentaux. On a pu constater dans les faits que le mouvement dans son ensemble était loin de suivre aussi clairement la voie tracée par le président Castro.

Nombreux étaient ceux qui avaient mal supporté l'attitude cubaine lors du sommet de la Havane, et particulièrement la manœuvre consistant à exclure le Cambodge démocratique, reconnu par la majorité des membres du mouvement, pour arriver à une situation de chaise vide, selon une procédure que beaucoup d'entre eux ont considérée comme viciée et contraire aux décisions du sommet des ministres qui avait précédé la réunion. Ce mécontentement est peut-être la cause de la non-élection de Cuba au Conseil de sécurité; on sait que le Mouvement des non-alignés jouit d'une majorité quasi automatique à l'Assemblée générale de l'ONU, on peut donc penser que certains d'entre eux $n$ 'ont 
pas soutenu la candidature de Cuba au moment du vote proprement dit.

Force est par ailleurs de constater que le mouvement des non-alignés se trouve divisé par de nombreux conflits: les questions de l'Afghanistan, du Kampuchea, du Sahara occidental ont été I'objet de discussions mouvementées à New Dehli. C'est d'ailleurs par la faute d'un autre conflit que le sommet s'est finalement tenu dans cette ville. En effet, la réunion devait initialement avoir lieu à Bagdad; le conflit entre I'Irak et l'Iran posait le problème de principe de la réunion d'une conférence au sommet dans un Etat qui se trouvait en guerre avec un autre membre du mouvement. Dans ces conditions, le choix s'est finalement porté sur New Dehli.

La conférence s'est donc ouverte, avec pour principal point d'incertitude l'occupation du siège du Kampuchea, les non-alignés étant divisés entre partisans du gouvernement Heng Samrin, appuyé par le Vietnam, et le gouvernement de coalition en exil, du prince Sihanouk. La solution finalement retenue fut identique à celle qui avait été trouvée à la Havane: le siège est resté vacant, aucune des deux délégations n'a été invitée.

New Dehli a été l'occasion d'un important recentrage du Mouvement, et les nombreux paragraphes qui semblent montrer dans leurs prises de position anti-impérialistes une certaine radicalisation sont certainement d'apparence trompeuse, dans le sens où le consensus extensif tel que pratiqué par le Mouvement permet le plus souvent à chaque Etat de placer la déclaration qui lui tient à cœur. Les orientations de fond montrent clairement un retour aux principes originels du Mouvement, tels que les défend par exemple la Yougoslavie.

Indira Gandhi, premier ministre de I'Inde, devenue présidente du Mouvement pour trois ans, a exprimé dans son discours d'ouverture son inquiétude devant l'équilibre de la terreur, qui est assuré par une poignée d'Etats surpuissants, sans que les autres pays puissent tenter quelque action que ce soit pour les détourner de cette escalade continuelle. Elle a également fait état de sa préoccupation devant la récession économique généralisée qui frappe durement les pays en développement, et devant le poids de la dette de 600 milliards de dollars qui repose sur ces derniers. Elle rappelait que le simple service de la dette engloutit un quart de toutes les recettes d'exportation du Tiers Monde. Elle appelait encore à la réunion d'une conférence destinée à créer un nouveau système monétaire international, orienté vers les pays en développement, et à l'instauration d'un réel dialogue entre les pays du Nord et du Sud, qui ne s'est pas encore réalisé jusqu'ici, selon elle. Indira Gandhi a déclaré que I'Inde et le Mouvement n'avaient ni allié ni ennemi naturels, évoquant le message amical que le président Reagan avait adressé au sommet. En matière économique, Indira Gandhi affir- 
mait: «Je ne crois ni aux délais ni aux pressions. Nous souhaitons des négociations globales. Les pays riches ont autant besoin de nous que nous avons besoin d'eux. Nous ne demandons ni pitié ni charité, mais une coopération mutuellement bénéfique. Si le Nord veut ignorer le Sud, ce sera à ses risques et périls."

Dans le domaine économique, les non-alignés se sont déclarés convaincus de «la futilité pour un seul pays ou un groupe de pays de tenter de trouver isolément des solutions aux problèmes économiques globaux du moment entre pays en développement et pays développés". Ils ont affirmé que "la macrogestion de l'économie mondiale et la promotion du développement devraient reposer sur une coopération économique mondiale dans les domaines du commerce, des matières premières, de la monnaie et des finances».

La conférence a souligné dans son programme d'action pour une coopération économique la nécessité «d'une refonte complète du système monétaire et financier international actuel, inéquitable et déphasé». Les non-alignés se déclarent également «préoccupés des pressions croissantes exercées par certains pays développés, particulièrement sur la Banque Mondiale et le $\mathrm{FMI}$ » afin que ces organisations adoptent "une conception de la conditionnalité et de l'octroi des prêts fondée sur des considérations d'ordre politique incompatibles avec les exigences du développement et de l'ajustement. La déclaration lance aussi une mise en garde contre les traitements simplistes prescrits pour résoudre les problèmes économiques, qui sont fondés sur certaines conceptions idéologiques et ne reconnaissent pas la diversité des systèmes économiques».

La conférence de New Dehli a également été l'occasion de faire une déclaration sur la coopération Sud-Sud. Celle-ci avait une importance particulière pour des pays tels que I'Inde et I'Egypte, avec un secteur industriel important. L'idée n'est pas de se substituer à la coopération Nord-Sud, mais de créer de nouveaux marchés permettant une coopération commerciale, financière et technique entre pays du Sud, et la mise en place d'industries de base, en complément aux relations déjà existantes, principalement avec les pays du Nord. Les efforts devraient aller d'abord à des productions agricoles vivrières et à la transformation de matières premières. Le but général est de permettre un renforcement de l'indépendance économique des non-alignés. L'idée de la création d'une banque des pays en développement avait également été soulevée, mais finalement abandonnée, les éventuels bailleurs de fonds ayant rappelé qu'ils faisaient face à des difficultés financières les empêchant d'envisager une telle entreprise à l'heure actuelle.

Les non-alignés ont exprimé le souhait que les nombreux points, qui allaient être repris pour la plupart dans la plate-forme de Buenos Aires du "Groupe des 77», soient discutés sérieusement à la CNUCED VI à Bel- 
grade. Les non-alignés estimaient en effet que cette conférence était une opportunité majeure de faire un tour d'horizon complet et global de la situation économique internationale et de son impact sur le commerce et le développement des pays du Sud. Les non-alignés souhaitaient une concertation et un échange d'informations entre pays débiteurs. Cette question a également été soulevée à Buenos Aires, elle a provoqué des réactions négatives de plusieurs Etats qui craignaient des incidences défavorables sur la renégociation de leur dette face aux organismes créditeurs.

Le sommet de Williamsburg entre les pays industrialisés en avril 1983 n'a fourni aucune réponse réelle aux propositions des non-alignés. Quoique la question de la dette des pays en développement ait occupé une partie des débats, une politique commune n'a pu être définie. Les discussions se sont concentrées sur la fermeté du dollar et la sousévaluation du yen japonais, préjudiciables aux pays de la CEE, et sur les exportations agricoles américaines, qui font concurrence à celles de l'Europe.

\section{Position de la Suisse}

La Suisse a participé en tant qu'invitée à la conférence. La délégation était dirigée par l'ambassadeur de Suisse en Inde, M. Peter Erni, et comprenait en outre l'ambassadeur Jean-Pierre Ritter, chef du Secrétariat politique du Département fédéral des affaires étrangères.

Depuis 1976, la Suisse a assisté, comme invité, à toutes les conférences au sommet (Colombo 1976, La Havane 1979) et à toutes les conférences des ministres des affaires étrangères des pays non-alignés (Belgrade 1978, New Dehli 1981). C'est aussi le cas des autres pays neutres d'Europe, ainsi la Finlande depuis 1964, I'Autriche depuis 1970 et la Suède depuis 1973. Les pays invités assistent aux séances plénières sans participer aux débats. Ils ne sont pas présents aux séances des commissions, contrairement aux observateurs.

A diverses reprises, cette présence, même modeste, de la Suisse a suscité dans notre pays une vive opposition de la part de certains milieux radicaux, démocrates du centre et démocrates-chrétiens. Suite à la conférence au sommet de la Havane en 1979, et aux prises de position de Fidel Castro sur les "alliés naturels" des non-alignés, le conseiller national saint-gallois Oehler (PDC) avait déclaré dans une interpellation que ce point de vue était en train de triompher et qu'en participant aux réunions des non-alignés, la Suissse mettait sa neutralité en péril. Le Conseil fédéral avait alors contesté cette argumentation, soulignant que la majorité des pays membres du groupe restaient favorables à une position médiane, indépendante de Moscou et de Washington. Le Conseil fédéral reconnaît que neutralité et nonalignement ne sont pas synonymes. Mais il estime que dans certains domaines importants, les deux notions ont des points de convergence. 
Comme les neutres, les non-alignés - dans leur majorité - s'efforcent de s'opposer aux tentatives des super-grands de dominer le monde et refusent d'adhérer à des pactes militaires. En outre, dans l'intérêt même de la Suisse, il vaut la peine de participer à un forum qui représente "l'écrasante majorité de la communauté internationale» et où se discutent "les principaux problèmes politiques de l'heure".

La question de passer du statut d'invité à celui d'observateur n'a jamais été évoquée, ni pour la Suisse, ni pour les autres pays européens invités. L'ambassadeur Ritter, de retour de New Dehli, déclarait que le statut d'invité correspond assez exactement aux similitudes aussi bien qu'aux divergences entre neutres et non-alignés de sorte que le passage représenterait une décision politique allant dans un sens nouveau.

La Suisse se trouve de manière générale quelque peu en retrait par rapport aux positions des autres neutres: la Suède prend souvent des positions très proches du mouvement, et la politique extérieure très dynamique du chancelier Kreisky amenait l'Autriche, jusqu'à récemment en tout cas, à prendre des positions parfois très affirmées, le conflit du Moyen-Orient en est un bon exemple. II faut toutefois souligner que même la Suède n'envisage pas de demander le statut d'observateur.

Quoique la Suisse soit un hôte relativement tardif du Mouvement, il semble bien que l'intérêt qu'elle lui porte aille croissant. II existe des occasions de collaboration entre les neutres et les non-alignés européens (Chypre, Malte, Yougoslavie) comme c'est le cas à la Conférence de Madrid sur la sécurité et la coopération en Europe (CSCE). Les neutres et les non-alignés étaient en effet chargés de rédiger le difficile projet de document final de la CSCE.

II y a donc de nombreux points communs entre les non-alignés et la Suisse, tels que le respect des principes de non-ingérence dans les affaires intérieures d'un Etat, l'indépendance et la souveraineté des membres de la communauté internationale, et le règlement pacifique des différends.

II est surtout très important, selon les autorités fédérales, qu'un pays hautement industrialisé comme la Suisse, pays du Nord, soit présent dans un forum international où il n'est pas face au Tiers Monde dans une position d'antagonisme d'intérêts, mais bien de dialogue et d'échange de vues.

\section{Sources}

Documents de la Conférence, New Dehli, mars 1983.

IFDA Special United Nations Service No 747, 14 avril 1983.

Le Monde Diplomatique, mars 1983. 
Le Monde, 1 - 15 mars 1983.

South, mai 1983.

Tagesanzeiger, NZZ, Tribune le Matin, 1-15 mars 1983.

\section{CONFERENCE MINISTERIELLE DU GATT}

Le protectionnisme ambiant n'a pas empêché les parties contractantes du GATT de se retrouver au niveau ministériel pour leur conférence sur la liberté du commerce mondial. Les négociations ont été ardues et se sont terminées sans autre résultat que l'adoption d'un programme de travail. Les perspectives d'une intégration plus poussée dans le système contractuel des échanges n'enthousiasment pas les pays en développement. La Suisse a joué un rôle actif lors de cette conférence et elle en juge les résultats positifs.

La 38ème session des parties contractantes du GATT s'est tenue du 22 au 30 novembre à Genève, du 24 au 29 novembre au nivau ministériel. C'était la première fois depuis 1973 que les ministres se retrouvaient, ce fait ayant éclipsé l'an passé les autres activités du GATT.

Le GATT rassemble aujourd'hui 89 pays qui s'adjugent environ $80 \%$ du commerce universel. Conclu en 1948, le traité du GATT impose certaines règles de conduite dans le choix d'une politique commerciale, afin que tous les Etats participants retirent un profit maximum de la libéralisation et de l'extension des échanges internationaux. Le traité du GATT repose sur les quatre piliers suivants:

- clause de la nation la plus favorisée: l'avantage commercial consenti à un partenaire doit immédiatement être étendu aux échanges avec tous les autres pays du GATT;

- refus des discriminations: aucun pays signataire du traité ne doit être défavorisé par rapport à d'autres;

- interdiction du protectionnisme: les marchandises étrangères et indigènes doivent être placées sur un pied d'égalité;

- interdiction des restrictions quantitatives.

Sept rondes de négociations ont déjà eu lieu, autant d'étapes dans I'abaissement des droits de douane sur les produits industriels. Le commerce des produits agricoles reste largement exclu de la libéralisation. Des restrictions quantitatives au commerce des textiles ont même été autorisées par le GATT dans le cadre de I'AMF (Accord multifibres).

Depuis la signature du traité du GATT, des facteurs nouveaux sont apparus. Citons l'entrée des pays en développement dans l'éconmie mondiale en tant qu'Etats indépendants, l'importance croissante des services dans le commerce international et le poids que leurs investissements à l'étranger confèrent aux opérations internes des sociétés transnationales. 


\section{Préparatifs de la conférence ministérielle du GATT}

$C^{\prime}$ est dans un climat de dépression économique et de protectionnisme croissant que le secrétariat du GATT et le groupe consultatif des 18 ont pris l'initiative de convoquer une conférence ministérielle en 1981. Les parties contractantes prirent une décision positive en novembre 1981 , lors de leur 37ème session.

On s'attendait généralement à voir les participants confirmer la validité des règlements multilatéraux qui régissent le commerce mondial et renforcer les mesures contre le protectionnisme. Cependant, les dispositions d'esprit dans lesquelles les divers pays et groupes d'Etats (EU, CEE, Japon, pays en développement) abordaient la conférence $n$ 'indiquaient nullement qu'ils allaient penser et agir en commun. Formé dans le sérail, un comité chargé des préparatifs prépara au cours de l'année un projet de déclaration ministérielle.

Au cours de cette phase préparatoire, on a discuté du choix d'un siège pour le GATT et de décisions possibles dans les domaines suivants:

- élargir la base contractuelle des droits et des devoirs dans les relations commerciales entre pays industriels et pays en développement. D'une part, il s'agirait dans les pays industriels d'améliorer l'accès au marché et de garantir le système des préférences douanières non réciproques, limitées dans le temps et délivrées de manière autonome, système instauré au cours des années 70. D'autre part, selon le niveau qu'ils ont déjà atteint, les pays en développement devraient envisager le moment où ils assumeraient des obligations plus étendues en matière de politique commerciale et où ils renonceraient aux traitements de faveur. Les pays en développement assumeraient peu à peu, selon les progrès économiques accomplis, une plus forte proportion des règlements et des devoirs d'un système commercial ouvert et multilatéral;

étudier à l'intérieur du GATT le développement des échanges entre pays du Sud par la conclusion d'ententes régionales et interrégionales sur la suppression des droits de douane et des entraves non tarifaires au commerce;

mieux utiliser les règlements du GATT en matière d'échanges agricoles et examiner si le GATT ne pourrait pas se manifester dans de nouveaux domaines (prestations de services, technologie de pointe et conditions d'investissements);

- redéfinir la clause de protection du GATT, qui autorise en certaines circonstances des mesures nationales de protection contre des importations envahissantes. Cette révision aurait notamment pour but d'englober les dispositions bilatérales sur les restrictions aux exportations qui ont été décidées de plus en plus souvent hors du GATT ces derniers temps; 
- enfin réviser au vu des expériences faites la procédure d'arbitrage du GATT en accordant plus d'importance au rôle assumé par des médiateurs neutres.

\section{Déroulement de la conférence ministérielle du GATT}

La conférence a été largement consacrée à la lecture de déclarations de principe qui réclamaient toutes une augmentation du volume des échanges internationaux et une résistance organisée contre la montée du protectionnisme. Les négociations proprement dites ont servi à rédiger le document final, négociations menées par un groupe directeur de neuf membres, dont la Suisse. Trois thèmes ardemment controversés ont inspiré de nouvelles propositions:

- la lutte contre le protectionnisme;

- la politique agricole;

- les services.

$D^{\prime}$ autres pourparlers $n$ 'ont longtemps pas permis de préparer un compromis entre les divers groupes de pays. Placé devant la nécessité de choisir si l'on devait se séparer sans résultats, la conférence fut prolongée et finit par adopter une déclaration de principe. Ce document ne propose pour ainsi dire aucun engagement de politique commerciale; c'est un programme de travail assez complet.

\section{Les résultats}

La première partie de la déclaration finale consacre la volonté des Etats signataires de s'en tenir à une politique commerciale hostile au protectionnisme et propice au système du GATT. Suit un paragraphe $7 \mathrm{~d}$ 'inspiration plutôt opérationnelle qui concerne le cap à faire prendre par la politique commerciale dans l'optique d'un programme de travail pour les années 80. Devraient être recherchés sans délai des compromis sur: les clauses multilatérales de protection; une meilleure application des principes du GATT dans le domaine agricole; une amélioration de la procédure $d$ 'arbitrage (la déclaration contenant déjà une décision opérationnelle); des activités et des règlements du GATT en relation avec les pays en développement et les possibiltés de libéraliser le commerce des textiles (seulement après l'échéance de l'AMF en mars 1986).

La déclaration finale reproduit aussi toute une série de décisions prises en vertu du programme de travail effectif du GATT: réductions quantitatives et autres entraves commerciales non tarifaires, douanes, produits tropicaux, adaptation aux structures et politique commerciale, commerce des produits contrefaits, exportation d'articles interdits à l'intérieur du pays, crédit à l'exportation pour biens d'investissement, commerce des vêtements et textiles, difficultés du commerce de certaines matières premières, commerce des technologies de pointe, répercussions commerciales des variations des cours de change, politi- 
que de double facturation, certificats d'origine, prestations de services.

II est patent que les pays en développement jouissent de certains privilèges dans le système du GATT. On leur permet notamment d'élever des barrières douanières et $d$ 'introduire des discriminations non tarifaires pour protéger leur développement. Les pays en développement espéraient que la conférence ministérielle abolirait les mesures protectionnistes des pays industriels dans le secteur des textiles et de l'habillement comme dans celui des produits agricoles et qu'on en viendrait, sur un plan général, à davantage de sécurité juridique et de stabilité dans les échanges internationaux.

La suppression des entraves au commerce n'a cependant pas dépassé le stade des discussions; les pays en développement ont pu constater que la contre-proposition de certains pays industriels désireux de les lier plus étroitement au système du GATT n'avait pas plus de succès. Des liens plus étroits auraient valu aux pays en développement de jouir de droits accrus et d'assumer davantage de charges selon l'état de leur développement; ils auraient dû admettre le principe de la graduation. La plupart des pays en développement se prononcèrent contre cette idée.

Les pays en développement finirent également par s'opposer à la proposition américaine de libéraliser le commerce des services; ils acceptèrent seulement que les pays intéressés fassent rédiger des études à ce sujet. La déclaration ministérielle n'en contient pas moins toute une série de décisions dues en partie à des initiatives présentées par les pays en développement, par exemple les passages concernant les produits tropicaux, les restrictions quantitatives, les textiles, les relations commerciales entre pays industriels et pays en développement et également la clause de protection concernant l'agriculture.

\section{L'attitude de la Suisse}

La Suisse joua un rôle actif durant la phase préparatoire. Ce rôle fut même de premier plan durant la conférence, notre pays faisant partie du groupe présidentiel. La Suisse considère la conférence ministérielle du GATT comme un événement positif, compte tenu des difficultés actuelles du commerce mondial et même si la conférence $n^{\prime}$ a pas répondu à tous les espoirs mis en elle. La délégation suisse était dirigée par I'ancien conseiller fédéral Honegger et par le secrétaire d'Etat Jolles; elle a présenté quelques propositions en son nom à la conférence. Après une profession de foi en l'honneur d'un commerce mondial ouvert et multilatéral et en faveur de l'amélioration du GATT, la Suisse précisa quelles priorités elle jugeait souhaitables: mise au point d'une procédure d'arbitrage efficace, nouvelle rédaction des articles concernant la clause de protection multilatérale, meilleure intégration des 
pays en développement dans le système commerciai mondial du GATT.

En ce qui concerne les pays en développement, la Suisse ciemanda à la conférence ministérielle de fixer les modalités selon lesquelles pays industriels et pays en développement conviendraient d'une meilleure intégration du Tiers Monde dans l'économie mondiale. La conférence, nous l'avons déjà dit, n'a pris aucune décision à son égard. La discussion se poursuivra dans les différents comités du GATT.

\section{Sources}

GATT, Activités en 1982.

GATT-Focus, 16-18/1982, 19/1982.

NZZ, 12-16-17-30.11 et 1-2.12.1982.

i3m actualités 9/1982.

\section{ORGANISATION DE COOPERATION ET DE DEVELOPPEMENT ECONOMIQUE (OCDE)}

C'est sous l'égide de l'OCDE que travaille le Comité d'aide au développement (CAD) dont le rôle central de forum des pays développés en matière d'aide publique au développement est désormais bien assis. Le CAD regroupe dixhuit pays industriels et la commission de la CEE. La Suisse en est membre depuis 1968.

Le Comité passe chaque année en revue les politiques d'aide de ses membres et évalue le volume, les conditions, les formes ainsi que la distribution géographique et sectorielle de leur APD ainsi que de leurs autres flux vers les pays en développement. La tâche du CAD consiste aussi à approfondir certains thèmes nécessitant une réflexion commune ou faisant l'objet des préoccupations de certains de ses membres. Le CAD est enfin le lieu où sont entrepris des efforts de coordination des politiques et d'harmonisation de certaines pratiques en matière d'APD. Parfois, ces travaux sont sanctionnés par l'élaboration de lignes directrices ou de recommandations adressées aux membres du CAD.

La Suisse a fait, en février 1982, l'objet d'un examen de son aide; cet examen était basé sur les prestations de l'année 1980. Les examinateurs ont jugé le volume de I'APD de notre pays peu satisfaisant et manifesté leur inquiétude face à l'impact sur celui-ci des mesures d'austérité budgétaire de la Confédération. Ils se sont par contre prononcés très positivement sur la qualité de l'aide publique suisse, en raison de son orientation en direction des pays les moins avancés et des conditions libérales auxquelles elle est octroyée. Les prestations de la Suisse feront à nouveau l'objet d'un examen, portant sur l'année 1982, au début de 1984 . 
La Suisse a par ailleurs participé à toute une série de réunions organisées par le CAD en 1982, certaines de caractère technique, d'autres portant sur des sujets plus politiques. Les principaux thèmes traités ont été:

a) la question du financement associé ou financement mixte, traitée par le groupe de travail du CAD sur les aspects financiers de l'aide: il s'agit de l'examen des diverses formes de combinaisons possibles entre des fonds d'origine publique et privée ainsi que des risques que cette pratique, qui tend à se renforcer et à se diversifier (en raison des efforts de relance économique des pays industrialisés), peut faire courir aux objectifs et principes de politique en matière d'APD tels qu'ils ont été définis jusqu'ici;

b) l'examen de la situation de la coopération multilatérale et de l'avenir de celle-ci: c'est le soutien actuellement faiblissant à ces organistions qui est à la base de cette préoccupation;

c) I'aide à la maintenance et la prise en charge des frais locaux et récurrents des projets de développement afin d'assister les pays pauvres à faire face à la crise actuelle; ainsi que la réorientation des politiques d'aide afin d'en tenir compte (aide à la balance des paiements et/ou prise en charge temporaire des frais locaux et d'entretien);

d) la question de la prise en considération, lors de la préparation et de la mise en œuvre des grands projets, de leur impact sur l'environnement.

La 21 ème assemblée annuelle du CAD à haut niveau, qui s'est tenue en décembre 1982, s'est penchée sur les perspectives économiques et financières des pays en développement dans cette période de crise économique dont souffrent particulièrement ces derniers. Un accent spécial fut piacé sur la situation des pays les plus pauvres et sur leurs besoins spécifiques dans les circonstances (aide à la maintenance et renforcement des services et équipements existants). Le point politiquement sensible du burden sharing (partage de l'effort) fut également traité; il s'agit d'éviter que les efforts d'accroissement de l'APD des uns soient négativement compensés par le recul de ces mêmes efforts de la part d'autres donateurs (en particulier de quelques grands). La discussion sur la coordination de l'aide et le dialogue sur les politiques (policy dialogue entre les gouvernements des pays donateurs, d'une part, et celui du pays partenaire bénéficiaire, de l'autre) s'est poursuivie à cette occasion.

Outre le $C A D$, dont les travaux portent spécifiquement sur les questions d'APD, existent au sein de I'OCDE bon nombre d'autres instances traitant de questions relevant des relations Nord-Sud. Ainsi les groupes sur les produits de base, sur les questions commerciales, sur les politiques agricoles, pour ne citer que ceux-ci. II existe en outre un groupe Nord-Sud regroupant tous les membres de I'OCDE (pays développés membres du CAD plus la Turquie et le Portugal) qui a une dou- 
ble tâche: d'une part, c'est dans son sein que se préparent les positions de membres de I'OCDE en vue de négociations internationales, telles la Conférence ministérielle du GATT ou la CNUCED; d'autre part, $s^{\prime} y$ effectuent toute une série d'efforts de réflexion sur les enjeux du dialogue Nord-Sud, en particulier sous I'angle de l'interdépendance. Les différentes facettes de ces réflexions portent sur les questions de technologie, de matières premières, d'énergie, de population, d'environnement, ainsi que sur celles commerciales et monétaires.

Le rapport sur ces réflexions en 1982 a été soumis sous forme d'un document de synthèse à la Conférence ministérielle de l'OCDE qui s'est tenue au début de 1983. L'une des préoccupations principales fut (une fois encore) la dimension Nord-Sud de la crise et l'importance de la reprise tant pour les pays développés que pour les pays en développement. La Suisse a participé à toutes ces réunions au cours desquelles les pays de l'OCDE cherchent à coordonner leurs positions.

\section{INSTITUTIONS FINANCIERES INTERNATIONALES}

Ce sont les pays du Tiers Monde non exportateurs de pétrole qui ont été les plus durement touchés par la crise financière internationale du début des années 80 . Ils ont vu enfler le déficit de leur balance des paiements et beaucoup d'entre eux ont vu leurs dettes s'accumuler d'une manière plus ou moins grave.

Divers facteurs ont contribué à détériorer la balance commerciale de la plupart des pays en développement. La baisse du produit des ventes de matières premières aux pays industriels de I'Occident n'a pas empêché une hausse des importations arrivant en sens inverse. Les termes de l'échange ont donc continué à se modifier au détriment des pays en développement. A l'échelle internationale, les pertes enregistrées à l'exportation par les pays en développement proviennent d'une stagnation mondiale; on peut même parler d'un authentique recul du commerce mondial.

Le recul du volume des échanges internationaux a été fortement influencé par la récession dans les pays industriels occidentaux et par le recours de plus en plus fréquent de ces pays-là à des mesures protectionnistes. Ajoutez, au plan du commerce intérieur, l'adoption d'une politique anti-inflationniste aux retombées négatives pour la demande et pour l'essor du commerce mondial.

Les déficits croissants de leur balance commerciale ont contraint les pays en développement à solliciter de plus en plus les marchés financiers internationaux, ceci afin de pouvoir couvrir dans l'immédiat leurs dépenses courantes. II y a des capitaux privés disponibles sur les places financières internationales, mais les emprunts se traitent à court 
terme et à des taux sans cesse en hausse. En chiffres nets, la dette des pays en développement non exportateurs de pétrole absorbe une part toujours plus forte du PNB et le service de cette dette s'accroît par rapport aux exportations.

L'année 1982-1983 a marqué un tournant sur les marchés financiers internationaux; on n'a plus parlé de déficit des balances nationales des paiements, mais d'une vraie crise de l'endettement. Si le prix des matières premières continue à tomber, si les échanges internationaux faiblissent et que les intérêts restent élevés, la solvabilité et la crédibilité de toute une série de pays en développement en seront ébranlées. Les prêts des banques privées ont fortement baissé en 1982 et en sont restés au même niveau durant le premier semestre 1983. Les consolidations d'emprunts ont augmenté.

Les mesures de rééchelonnement des dettes publiques ou garanties par les pouvoirs publics sont préparés au Club de Paris. Les débiteurs sont surtout des pays en développement particulièrement démunis et qui ne peuvent songer à emprunter auprès des banques privées. Le Club de Londres est compétent pour les rééchelonnements assumés par le secteur des banques privées. On y négocie surtout la consolidation des dettes des pays latino-américains.

Les rééchelonnements nécessaires peuvent être adoptés pour venir à bout d'une crise des liquidités due à la conjoncture ou en cas d'insolvabilité structurelle d'un pays.

Pour la première fois, il a fallu faire appel aux ressources de la BRI en faveur de divers pays en développement, vu l'impossibilité où ils étaient de s'adresser aux banques privées et à cause de la lenteur des pourparlers qu'on leur imposait. Le FMI n'accorde de crédits que si le bénéficiaire prend des mesures d'austérité à court terme et s'engage à longue échéance dans certains programmes de réformes. La Banque mondiale et les banques régionales de développement ouvrent des crédits à moyen terme pour financer certains secteurs ou projets. C'est l'ensemble de ces mesures qui est censé rétablir l'équilibre des balances commerciales.

Le tableau suivant permet de voir quels pays en développement, à l'exclusion de la Pologne, ont participé en 1982-1983 à des négociations sur la reconversion de leurs dettes. Le tableau fait également apparaître les institutions qui ont participé à ces négociations (Club de Paris pour les crédits publics, Club de Londres pour les crédits privés). 
REECHELONNEMENT MULTILATERAUX 1982/1983

( en millions de dollars)

\begin{tabular}{|c|c|c|c|c|}
\hline & \multicolumn{2}{|c|}{$\begin{array}{l}\text { CLUB DE PARIS } \\
\text { (crédits publics) }\end{array}$} & \multicolumn{2}{|c|}{$\begin{array}{l}\text { CLUB DE LONDRES } \\
\text { (crédits privés) }\end{array}$} \\
\hline & 1982 & 1983 & 1982 & 1983 \\
\hline $\begin{array}{l}\text { ARGENTINE } \\
\text { BOLIVIE }\end{array}$ & & & & e.c.n. \\
\hline BRESIL & & & & e.c.n. \\
\hline CHILI & & & & e.c.n. \\
\hline COSTA RICA & & 215 & & e.c.n. \\
\hline CUBA & & & & e.c.n. \\
\hline REP. DOMINICAINE & & & & e.c.n. \\
\hline EQUATEUR & & & & e.c.n. \\
\hline GUYANE & & & 14 & e.c.n. \\
\hline HONDURAS & & & & e.c.n. \\
\hline LIBERIA & & & 29 & \\
\hline MADAGASCAR & 107 & & & e.c.n. \\
\hline MALAWI & 42 & & & e.c.n. \\
\hline MEXIQUE & & & & e.c.n. \\
\hline NICARAGUA & & & 55 & \\
\hline OUGANDA & 22 & & & e.c.n. \\
\hline ( POLOGNE) & & & $(5350)$ & \\
\hline ROUMANIE & 234 & & 1544 & \\
\hline SENEGAL & 84 & & & \\
\hline SOUDAN & 400 & 300 & & \\
\hline TOGO & & 181 & & e.c.n. \\
\hline TURQUIE & & & 3100 & \\
\hline YOUGOSLAVIE & & & & \\
\hline
\end{tabular}

Sources: Banque mondiale, rapport sur le développement 1983, FMil 


\subsection{Banque des règlements internationaux (BRI)}

En 1982-1983, la BRI a accordé pour la première fois à plusieurs pays en développement d'importants crédits transitoires. Ces mesures ont été prises sur la foi des négociations menées par les divers pays débiteurs avec le FMI et les banques créancières privées. Pour pouvoir ouvrir ces crédits, la BRI a dû recourir au financement des banques centrales de divers pays membres, riches évidemment.

Le but de la BRI, fondée en 1930, est de développer la coopération entre les banques d'émission. Elle y parvient en organisant des réunions mensuelles sur les problèmes monétaires entre leurs directeurs. $\mathrm{La} \mathrm{BRI}$ convoque également des consultations bilatérales quand il faut prendre des mesures d'ordre monétaire nationales ou internationales. Enfin, on réalise d'un commun accord certaines opérations monétaires ou relevant de l'aide financière. Le président actuel de la BRI est F. Leutwiler, qui est en même temps président du directoire de la BNS.

Le pays le plus endetté est le Mexique qui a demandé en août 1982 un crédit transitoire. La BRI mit à la disposition de la Banque centrale du Mexique un crédit à court terme de 0,925 milliards de dollars EU, la Banque centrale américaine en faisant simultanément autant. Le crédit de la BRI fut transféré en trois tranches à fin août 1982, à mi-novembre 1982 et à mi-décembre 1982. Dans l'intervalle, le FMI avait également accordé un crédit au Mexique. Le Brésil, autre vedette de l'endettement, s'adressa à la BRI en novembre. La demande portant sur le préfinancement du montant que le FMI ne pourrait débloquer que par la suite. La BRI accorda finalement au Brésil un crédit de soutien de 1,45 milliard de dollars EU. Le Brésil a dû renvoyer au début de juin le remboursement d'un crédit de $\mathbf{4 0 0}$ millions de dollars EU dû à la BRI.

L'Argentine demanda en octobre 1982 un crédit stand-by de 500 millions de dollars EU qui lui fut alloué en décembre. C'est en septembre 1982 déjà que la Yougoslavie présenta une demande de crédit transitoire pour un montant de $\mathbf{5 0 0}$ millions de dollars EU qui lui fut accordé en mars 1983. Enfin, en mai 1983, le Chili demanda 200 millions de dollars EU à la BRI pour faciliter le rééchelonnement de sa dette.

La BNS a participé à l'octroi de ces crédits transitoires en ouvrant de nouveaux crédits à la BRI. Pour le crédit au Mexique, elle déposa une garantie de 25 millions de dollars EU qui fut de $\mathbf{3 0}$ millions de dollars EU dans le cas du Brésil et de 25 millions de dollars EU en faveur de I'Argentine. La Suisse a participé à l'octroi du crédit à la Yougoslavie pour un montant de 40 millions de dollars EU. La Confédération a garanti à son tour les participations de la BNS à ces crédits transitoires, en vertu de l'arrêté fédéral sur la participation de la Suisse aux mesures financières internationales. 


\section{Sources}

Banque des règlements internationaux, 53ème rapport annuel, Bâle 1983. Banque nationale suisse, 75ème rapport annuel, Berne 1982.

\subsection{Fonds monétaire international}

Les crédits du FMI et les mesures d'ajustement jouent un grand rôle quand il s'agit de rétablir l'équilibre des balances des paiements. Lors de la réunion de février du comité intérimaire du FMI - vote de la 8ème augmentation des quotas; - décision d'augmenter le montant réservé aux AGE et d'en assurer une plus large distribution. Un tableau renseigne sur l'assistance fournie par le FMI.

\section{La 37ème conférence annuelle}

Du 6 au 9 septembre 1982 à Toronto, la 37 ème conférence annuelle du FMl et de la Banque mondiale eut pour thème central la 8ème révision de l'attribution des quotas du Fonds monétaire aux membres ordi naires. La Suisse fut le seul Etat à pouvoir participer à cette conférence avec le statut d'observateur.

Si I'on a, dans l'actuelle atmosphère d'inquiétude qui pèse sur le système financier, discuté d'une élévation des quotas, c'est parce que les grands et petits pays débiteurs ont vu s'enfler leurs difficultés de paiement. La question s'est posée de savoir si le FMI disposait de fonds suffisants pour remplir les obligations financières qui lui incombent.

Lors d'une séance préparatoire, les chefs des délégations des cinq premiers pays industriels (EU, Japon, RFA, Grande-Bretagne et France) se prononcèrent avec le Club des Dix des pays industriels pour une politique de lutte contre l'inflation et d'adaptation des structures nationales à un marché mondial ouvert, et cela malgré la récession. Ils envisageaient aussi de mettre à la disposition du FMI et des AGE des montants suffisants et de réviser rapidement les quotas pour parer à des difficultés de paiement de plus en plus inquiétantes.

Le groupe des 24, composé de représentants des pays en développement, reconnut la possibilité d'un effondrement financier et regretta la rigueur accrue du FMI dans I'octroi de ses crédits. Ce groupe demanda l'adoption d'un programme conjoncturel d'envergure mondiale et l'augmentation des dépenses au titre de la coopération multilatérale au développement.

Avant même l'ouverture de la conférence annuelle, le comité intérimaire du FMI tomba d'accord pour décider au printemps 1983 déjà de la 8ème augmentation des quotas. L'opposition de EU ne lui permit cependant pas de s'entendre sur une nouvelle augmentation des DTS (droits de tirage spéciaux). 
Pour répondre aux besoins croissants en disponibilités servant à équilibrer les balances des paiements, les gouverneurs donnèrent leur assentiment à un relèvement des quotas lors de la 8 ème révision. La discussion porta sur une augmentation de 50 à $100 \%$. Les gouverneurs proposèrent de trancher lors de la réunion ultérieure du comité intérimaire, au printemps 1983. Le FMI fut en outre prié de voir si les instruments dont il dispose suffiront à parer à des difficultés accrues du système financier international. Les EU proposèrent la création d'un fonds spécial permanent auquel tous les membres pourraient recourir en cas de grave crise des finances internationales.

\section{Réunion du comité intérimaire et du comité de développement}

$\mathrm{Vu}$ les difficultés financières internationales, la réunion de printemps du comité intérimaire fut avancée aux 10 et 11 février, à Washington. A l'occasion de la 8ème augmentation des quotas, le comité intérimaire décida de porter les droits de tirage spéciaux de 61 à 90 milliards. Les EU s'opposèrent à une augmentation plus prononcée. Si le gouvernement des EU est d'accord, cette augmentation des quotas de $47,4 \%$ devrait être mise à la disposition du FMI dès la fin de 1983. Les EU avaient commencé par proposer $40 \%$ d'augmentation, alors que les pays en développement proposaient $100 \%$. Même si l'augmentation des quotas intervient rapidement, les liquidités du FMI n'en seront guère améliorées vu l'endettement accru. L'augmentation des quotas est allée de pair avec une nouvelle définition des quotas pays par pays. Le Club des Dix mobilise maintenant $55,04 \%$ des voix; dans I'ensemble, les pays industriels ont pu augmenter légèrement le nombre de leurs voix. Les gouverneurs du FMI ayant donné leur assentiment à I'augmentation des quotas, il appartient désormais aux gouvernements de la ratifier jusqu'à fin novembre 1983. On parviendrait ainsi à boucler la 8ème révision des quotas deux ans plus tôt que prévu. En attendant, le FMI ne dispose plus que de moyens limités. Les gouverneurs ont en outre convenu d'élargir et d'augmenter les AGE. Cette opération améliore les capacités de refinancement du FMI et remédie d'avance à son éventuel manque de liquidités.

Les 28 et 29 avril 1983, à la réunion du comité de développement, les représentants des pays en développement renouvelèrent leur demande d'un programme conjoncturel d'envergure mondiale, alors que les pays industriels voulaient s'en tenir à la voie retenue, la lutte contre l'inflation. Le comité estime qu'il faut étendre l'aide financière multilatérale et coopérer plus étroitement avec la Banque mondiale, le FMI et le GATT. Le secrétaire d'Etat Jolles représentait la Suisse à cette réunion du comité. 


\section{Les prestations courantes du FMI}

Le tableau ci-dessous indique ce que furent les prestations courantes du Fonds pour aider divers pays membres à surmonter le déséquilibre de leur balance des paiements. II fait le point au 30 juin 1983 des accords généraux d'emprunt ou des crédits élargis octroyés par le FMI. A fin juin 1983, le FMI avait financé au cours des 12 mois précédents des accords généraux d'emprunt pour un montant de 8,4 milliards de DTS. Au total, 33 accords généraux d'emprunt pour une valeur de 8,6 milliards de DTS et 9 accords de crédit élargi d'un montant total de 15,6 milliards de DTS étaient en vigueur. Le montant global des engagements contractés s'élevait à 24,2 milliards de DTS.

La définition de ces accords s'énonce ainsi: «Par accord général d'emprunt, on désigne une décision du Fonds donnant à un membre l'assurance qu'il pourra, durant un certain temps et pour un certain montant, effectuer des tirages pour rééquilibrer sa balance des paiements.» En règle générale, les crédits élargis ne se distinguent des précédents que par leur plus longue période de validité.

En concluant ces accords, le FMI exige du pays membre un programme d'ajustement. Selon les termes employés par M. de Larosière, directeur du FMI, dans un discours prononcé à l'Université de Neuchâtel le 3 mars 1983, ces crédits doivent soutenir l'activité économique des pays bénéficiaires. Ils doivent en fait

- garantir envers d'autres créanciers un financement direct ou résultant de leur influence positive;

- rétablir la croissance économique grâce aux mesures du programme d'ajustement;

- grâce aux mesures orientées vers l'extérieur, stimuler les processus d'ajustement compatibles avec les intérêts légitimes des partenaires commerciaux et contribuer ainsi à des ajustements internationaux équitables.

\section{Sources}

IMF-Survey, Vol. 12/13 1982-1983.

FMI Memorandum.

J. de Larosière, Le FMI et les pays en développement, Université de Neuchâtel, 1983.

R. Gerster, Fallstricke der Verschuldung, Bâle 1982.

NZZ, 4-7, 11-12.9.1982, 9, 14.2., 6, 18.4., 7-8.5.1983.

TA, 6.9.1982, 7, 14.2.1983. 


\section{ACCORDS DE CONFIRMATION ET ACCORDS ELARGIS DE CONFIRMATION ( entrés en vigueur le 30 juin 1983, en milliers de DST )}

a) Accords de confirmation

Membres

\section{Argentinien}

Bangladesch

Barbados

Chile

Costa Rica

El Salvador

Guinea

Haiti

Honduras

Jugoslawien

Kenia

Liberia

Madagaskar

Malawi

Mauritius

Panama

Philippinen

Rumänien

Salomoninseln

Sambia

Senegal

Simbabwe

Somalia

Südafrika

Sudan

Thailand

Togo

Türkei

Uganda

Ungarn

Uruguay

Westsamoa

Zentralafrikanische Rep.

Total a)

$\begin{aligned} 1500000 & \text { Brasilien } \\ 68400 & \text { Dominica } \\ 31875 & \text { Dominikanische Rep. } \\ 500000 & \text { Elfenbeinküste } \\ 92250 & \text { Indien } \\ 43000 & \text { Jamaika } \\ 25000 & \text { Mexiko } \\ 34500 & \text { Pakistan } \\ 76500 & \text { Peru } \\ 1662000 & \\ 175950 & \text { Total b) }\end{aligned}$

55000

51000

22000

49500

150000

315000

1102500

2400

211500

47250

300000

60000

364000

170000

271500

21375

225000

112500

475000

378000

3375

18000

8614375 b) Accords élargis de confirmation Membres

Brasilien

Dominica

4239375

8550

371250

484500

5000000

477700

3410625

919000

650000

15561000

Source: IWF-Finanzabteilung 


\subsection{Accords généraux d'emprunt et Club des Dix}

Le Club des Dix a décidé de porter le montant des AGE à 17 milliards de DTS La Suisse doit devenir membre à part entière du Club des Dix et participer au relèvement des DTS.

\section{L'augmentation des AGE}

Le Club des Dix qui regroupe dix pays industriels occidentaux et la Suisse en tant que membre associé est, hors du FMI et sur la même ligne que lui, le plus important forum de la politique monétaire.

Les Accords généraux d'emprunt (AGE) ont été passés en 1962 entre dix pays industriels occidentaux et le FMI. Leur but est de fournir à titre intérimaire aux pays débiteurs des crédits bilatéraux et multilatéraux en fonds publics, en passant par le FMI, jusqu'à ce que ces pays aient retrouvé leur crédit aux yeux des prêteurs privés. Les AGE fournissent ainsi un complément aux activités du FMI. Quand certains pays membres effectuent des tirages élevés, le FMI court le risque de manquer de liquidités. Dans ces cas-là, il peut recourir aux AGE. Selon les nouveaux $A G E$, le FMI doit pouvoir recevoir des pays membres du Club des Dix des crédits représentant un maximum de 17 milliards de DTS. Jusqu'alors, les crédits alloués au nom des AGE ne portaient que sur un maximum de 6,5 milliards de DTS et n'étaient accessibles qu'aux membres du Club des Dix.

C'est au début de 1983 que les membres du Club des Dix décidèrent de ce relèvement et d'une nouvelle répartition des quotes-parts des crédits disponibles en vertu des engagements pris en 1962. Ils décidèrent en outre qu'en cas de crise financière internationale, des pays tiers, n'étant donc pas membres du Club des Dix, pouvaient recevoir des contributions en vertu des AGE. Cette disposition permet à l'avenir $d^{\prime}$ avancer des fonds à des pays en développement. Dans le sens contraire, des pays ne participant pas à l'accord - on a sans doute pensé à certains pays de l'OPEP - doivent pouvoir fournir leur contribution. Des ressources plus abondantes devraient être disponibles dès le deuxième semestre de 1984. Après cette révision des AGE par le Club des Dix, le directoire exécutif du FMI accepta également les modifications intervenues.

\section{La Suisse souhaite être membre à part entière}

En janvier 1983, la Suisse a fait une demande pour devenir membre à part entière du Club des Dix. Les membres actuels seraient disposés à admettre la Suisse parmi eux, même si elle ne fait pas partie du FMI. Notre pays est membre associé du Club des Dix depuis 1964 déjà et a pris part à diverses opérations de crédit.

Le Conseil fédéral a publié le 2 août 1983 un «message sur l'adhésion 
de la Suisse aux Accords généraux d'emprunt". On y invoque à l'appui de notre demande d'admission les liens économiques étroits qui relient la Suisse à l'étranger et l'intérêt que notre pays éprouve en conséquence pour le maintien de marchés monétaires et financiers bien organisés au plan international. La participation de la Suisse aux nouveaux AGE serait calculée à 1.020 milliards de DTS, soit $6 \%$ du total des engagements garantis. Etre membre de plein droit du Club des Dix signifie qu'on parle à égalité avec les autres membres. Cependant, la Suisse ne peut toujours exercer aucune influence sur l'usage que le FMI fait de ces crédits. La prochaine attribution de prêts par la BNS se fera sans la garantie de la Confédération. Selon le message du Conseil fédéral, la décision d'entrer dans le Club des Dix n'est pas soumise au référendum facultatif.

Lors d'une conférence de presse réunie le 9 septembre 1983 à Berne, la communauté de travail Swissaid/Action de Carême/Pain pour le Prochain/Helvetas a pris position sur ce projet d'entrée au Club des Dix. Elle a regretté qu'on n'ait pas tenu compte de la politique de développement en demandant l'entrée de la Suisse aux AGE; elle souhaite que le Parlement soumette cette décision au référendum.

\section{Sources}

Bbl II 1093, pp. 1367 ss.

NZZ, 20.1.1983.

i3m-actualités 7/1983.

\subsection{Rééchelonnement des dettes au Club de Paris}

C'est au Club de Paris que les représentants des Etats créanciers coordonnent leurs opérations de rééchelonnement des dettes. Cette institution informelle joue un rôle essentiel dans ces opérations. Les démarches sont coordonnées pour éviter la concurrence. Des négociations réunissent $d$ 'abord les représentants du Club de Paris et ceux du pays débiteur, des recommandations sont adoptées et un accord bilatéral est signé.

Fin 1982, on arrêta d'abord les modalités de la consolidation des dettes commerciales et des emprunts gouvernementaux que la Roumanie aurait dû rembourser cette année-là. Le total des dettes garanties à consolider par la Suisse s'élève ici à 40 millions de francs.

A mi-avril, les représentants du Club de Paris, dont la Suisse, tombèrent $d$ 'accord pour assurer le rééchelonnement des emprunts garantis par l'Etat que le Togo aurait dû rembourser en 1982. A fin 1982 déjà, on avait consolidé les crédits commerciaux venus à échéance en 1981 et 1982 et souscrits par 15 Etats créanciers en faveur du Togo, dont la Suisse. En mai 1983, on mit au point le dispositif de consolidation des 
dettes dues en 1983 par ce même Etat. A fin juin 1983, le Mexique conclut avec 16 Etats créanciers un accord de restructuration des dettes extérieures de son secteur privé. II s'agit d'un montant de 2 milliards de dollars EU sur une dette extérieure mexicaine globale de 83 milliards de dollars EU.

A fin juillet 1983, 13 Etats créanciers de l'Equateur, dont la Suisse, se mirent d'accord pour conclure des conventions bilatérales de rééchelonnement de la dette. II s'agit d'un montant global de 110 millions de dollars EU. A fin juillet 1983, 20 Etats créanciers du Pérou, dont la Suisse, décidèrent de consolider les dettes du Pérou pour un montant d'un milliard de dollars EU. D'autres pourparlers en vue d'un rééchelonnement des dettes sont en cours avec Cuba.

\section{Sources}

NZZ 19, 24.4, 20.5, 2-3.7, 28.7, 30-31.7.1983.

\subsection{La Banque mondiale}

La Banque mondiale a élargi ses possibilités de cofinancement et adopté un programme d'actions extraordinaires. Les négociations concernant I'AID VII sont en cours. Les EU souhaitent réduire leur contribution. M. Clausen, le président de la Banque mondiale, a fait une courte visite en Suisse.

Les rentrées de fonds et les engagements de prêts de la Banque mondiale ont de nouveau atteint un niveau record l'an passé. En comparaison de l'année précédente, les taux d'intérêt de prêts alloués à des pays en développement ont baissé. Le marché suisse des capitaux a été fortement mis à contribution par la Banque mondiale.

Pour 1982-1983, les rentrées de fonds ont atteint 10,3 milliards de dollars EU et les crédits accordés un total de 14,4 milliards de dollars EU, dont 3,3 milliards ont passé par I'AID. Le montant total des versements effectués par la banque I'an passé s'est établi à 33,7 milliards de dollars EU. Les dettes contractées par la Banque mondiale s'élevaient fin juin 1982 à 39,4 milliards de dollars EU au total, ce qui fait d'elle l'un des plus gros débiteurs étrangers sur les principales places financières. Les prêts à moyen et long terme étaient à raison de $29 \%$ libellés en francs suisses.

Pour la première fois, la banque a aussi accepté des dépôts à court terme à des taux d'intérêt variables. Elle entend se montrer plus souple dans la mobilisation de ses ressources et être à même de mieux contrôler le coût de ses avoirs étrangers. II peut en résulter un renchérissement des crédits ouverts aux emprunteurs.

La banque a en outre décidé d'élargir les possibilités de cofinance- 
ment. Celles-ci seront au nombre de trois. II s'agit d'abord d'une participation directe à un prêt commercial servant à financer des projets de développement. La banque peut ainsi compléter par sa participation à un crédit commercial les ressources qu'elle désirait mettre directement à la disposition d'un projet. Deuxièmement, elle peut aussi s'engager à payer, le cas échéant, le reliquat d'une dette ou, troisièmement, garantir le remboursement du solde dû sur l'ensemble d'une opération. On espère ainsi augmenter le flux des capitaux privés venant financer des projets de la Banque mondiale. Ayant resserré leurs liens avec la Banque mondiale, les banques privées pourront octroyer des crédits dans un climat de plus grande sécurité. Ces possibilités de cofinancement donneront enfin aux pays en développement l'occasion de maintenir plus longtemps leurs dettes aux conditions du marché.

De 1983 à 1985, la Banque mondiale a l'intention de réaliser un programme d'actions extraordinaires. II s'agit d'aider les pays en développement à surmonter la crise actuelle de l'économie internationale et à maintenir le rythme de leur croissance. Le programme en question comporte un relèvement des versements chiffré à 2 milliards de dollars EU. II ne touche pas aux crédits de I'AID. II permettra de financer des modernisations de structures, d'accorder des prêts sectoriels et d'autres qui permettront une participation plus élevée aux frais de certains projets. Des conseils en politique économique et coordination internationale viendront compléter les appuis financiers. La Banque mondiale élargit ainsi son aide liée aux projets.

\section{$A / D$}

L'AID a connu de graves difficultés financières au cours de l'exercice 1982-1983. Les Etats-Unis, son principal donateur, ont prolongé jusqu'en 1985 la validité de leurs contributions à I'AID VI.

Considérant I'attitude des EU, divers Etats européens (France, PaysBas, Suède, Norvège, Danemark) et le Canada versent à un fonds parallèle leurs contributions pour 1982-1983. Les prêts alloués par ce fonds sont liés aux commandes passées dans les Etats qui I'alimentent.

Lors de la réunion FMI/Banque mondiale, les pays donateurs, à l'exception des EU, sont tombés d'accord pour tenir entièrement leurs engagements en 1983. Ils fournissent encore une contribution supplémentaire globale de 2 milliards de dollars EU sous la forme d'un crédit transitoire. Faute de quoi, I'AID n'aurait pas eu de quoi fonctionner dès 1984.

Les tractations concernant la gestion financière courante sont allées de pair avec les discussions sur le 7ème réapprovisionnement du Fonds de I'AID. Lors d'une première série d'entretiens, à fin novembre 1982, la Banque mondiale fit savoir que I'AID devrait pouvoir disposer 
dès le 1er juillet 1984 de 16 milliards de dollars EU pour trois ans, c'est à cette condition qu'elle pourrait maintenir le volume réel de ses activités. Les EU annoncèrent que, quoi qu'il en soit, ils réduiraient leurs prestations. Dans ce climat de tension, on envisagea la possibilité d'allouer les prêts de I'AID à des conditions plus dures. En en réduisant la durée, en en relevant de manière sélective les taux d'intérêt, en les octroyant selon des critères plus draconiens.

Mi-juillet à Tokyo, lors de la quatrième rencontre des pays donateurs, les EU firent savoir qu'ils réduiraient leur contribution à I'AID VII à $25 \%$ au maximum de l'augmentation totale des fonds ou à 750 millions de dollars EU par an. Ce qui signifie qu'au cours des trois années qui viennent, I'AID ne disposerait plus que de 9 milliards de dollars EU. Les autres pays donateurs $n$ 'ont pas voulu admettre cette réduction massive du financement de I'AID dont les activités dans les pays les moins avancés, auxquels l'agence accorde à des conditions favorables des crédits pour leur développement, devraient être sensiblement réduites.

Les difficultés financières de I'AID font que la Suisse est de nouveau interpellée en tant que pays donateur éventuel. D'autant plus que les commandes passées jusqu'ici à l'économie suisse et payées sur des crédits de I'AID représentent un multiple des contributions helvétiques. Depuis la création de I'AID, la Suisse a reçu 2,3\% de I'ensemble des commandes et n'a participé au financement de I'AID qu'à raison de $0,37 \%$. Le Conseil fédéral a bien fait savoir que la Suisse s'intéressait en principe à une entrée au FMl et à la Banque mondiale, mais la discussion politique à ce sujet n'a pas encore été entamée.

A l'invitation de la BNS, le président de la Banque mondiale fit une visite en Suisse le 12 janvier 1983. Un éventuel soutien financier de I'AID par la Suisse fut alors évoqué. Le président Clausen s'entretint avec des représentants de la BNS, d'autres banques et sociétés d'assurances, ainsi qu'avec des délégués du Conseil fédéral et de l'administration. On discuta des liens de la Suisse avec la Banque mondiale, de la participation de notre pays à I'AID VI et de la situation financière dans laquelle se trouvait alors la Banque mondiale. Clausen souligna l'importance du marché suisse des capitaux pour la Banque mondiale et s'enquit d'une possible participation de notre pays à I'AID VI. Le conseiller fédéral Furgler fit valoir certaines réserves de caractère politique et financier. Une contribution à I'AID ne pourrait guère être prélevée sur les sommes actuellement dévolues à la coopération au développement. La possibilité que la Suisse participe plus fortement au cofinancement de divers projets de I'AID n'est pas exclue. Les montants alloués à ces cofinancements seraient cependant un peu plus modestes qu'une participation financière direct de la Suisse à I'AID.

\section{Sources}

NZZ, 9.8, 10.9, 26.11.1982; 1, 7.2, 15, 22.7.1983.

TA, 1.12.1982, Basler Zeitung, 15..1.1983. 


\subsection{Aide financière internationale à la Yougoslavie}

Le Département fédéral des affaires étrangères a organisé les 6-7 et les 18-19 janvier 1983 la "Conférence de Berne sur une aide financière internationale à la Yougoslavie». Fin 1982, les dettes extérieures de la Yougoslavie s'élevaient à 19,8 millions de dollars EU et le pays frôlait la cessation de paiements. $C^{\prime}$ est à la demande du gouvernement yougoslave, demande appuyée par les EU, la France et le FMI, que ces négociations financières furent organisées en Suisse.

Les représentants de 15 gouvernements de pays industriels occidentaux, dont la Suisse, un observateur du Koweït, des représentants du FMl et de la Banque mondiale prirent part à cette conférence. On décida de renforcer la coopération économique avec la Yougoslavie en recommandant aux gouvernements intéressés de mettre en 1983 à la disposition de ce pays un nouveau crédit à moyen terme d'un montant de 1,35 milliard de dollars EU, dont 0,25 milliard de pure aide financière. Cette décision a nécessité des négociations bilatérales qui sont arrivées pour la plupart à leur terme dans l'intervalle.

Le FMI avait mis au point un programme d'ajustement économique dès avant la conférence et il avait accordé un crédit de soutien. La Banque mondiale a également participé à cette aide financière et la BRI a alloué à la Yougoslavie un crédit transitoire de $\mathbf{5 0 0}$ millions de dollars EU.

La Yougoslavie s'est engagée simultanément dans des négociations avec le secteur bancaire privé. 600 banques privées environ ont laissé entrevoir à la Yougoslavie la possibilité d'emprunter environ 2 milliards de dollars EU (1,4 milliard pour des opérations de refinancement et 600 millions en emprunts nouveaux).

La Suisse a été l'organisatrice et la coordinatrice de cette conférence et elle I'a fait au nom de sa politique étrangère et de ses intérêts commerciaux. Sa participation à l'aide financière en fonds publics s'est élevée à environ 90 millions de dollars EU. Il s'agissait là de nouveaux crédits à l'exportation et d'un prêt purement financier. La BNS a en outre participé au crédit transitoire de la BRI en garantissant un montant de 40 millions de dollars EU.

\section{Sources}

NZZ, 11, 21, 15.1, 28.3, 18.4, 16.6, 7.7.1983.

DFAE, R. Probst, L'endettement dans le monde actuel, 26.4.1983. 